UNIVERSIDADE DE SÃo PAULO

INSTITUTO DE QUÍMICA

\title{
NANOMATERIAIS HÍBRIDOS DE PORFIRINAS SUPRAMOLECULARES E NANOPARTÍCULAS DE OURO E SUAS APLICAÇÕES EM DISPOSITIVOS
}

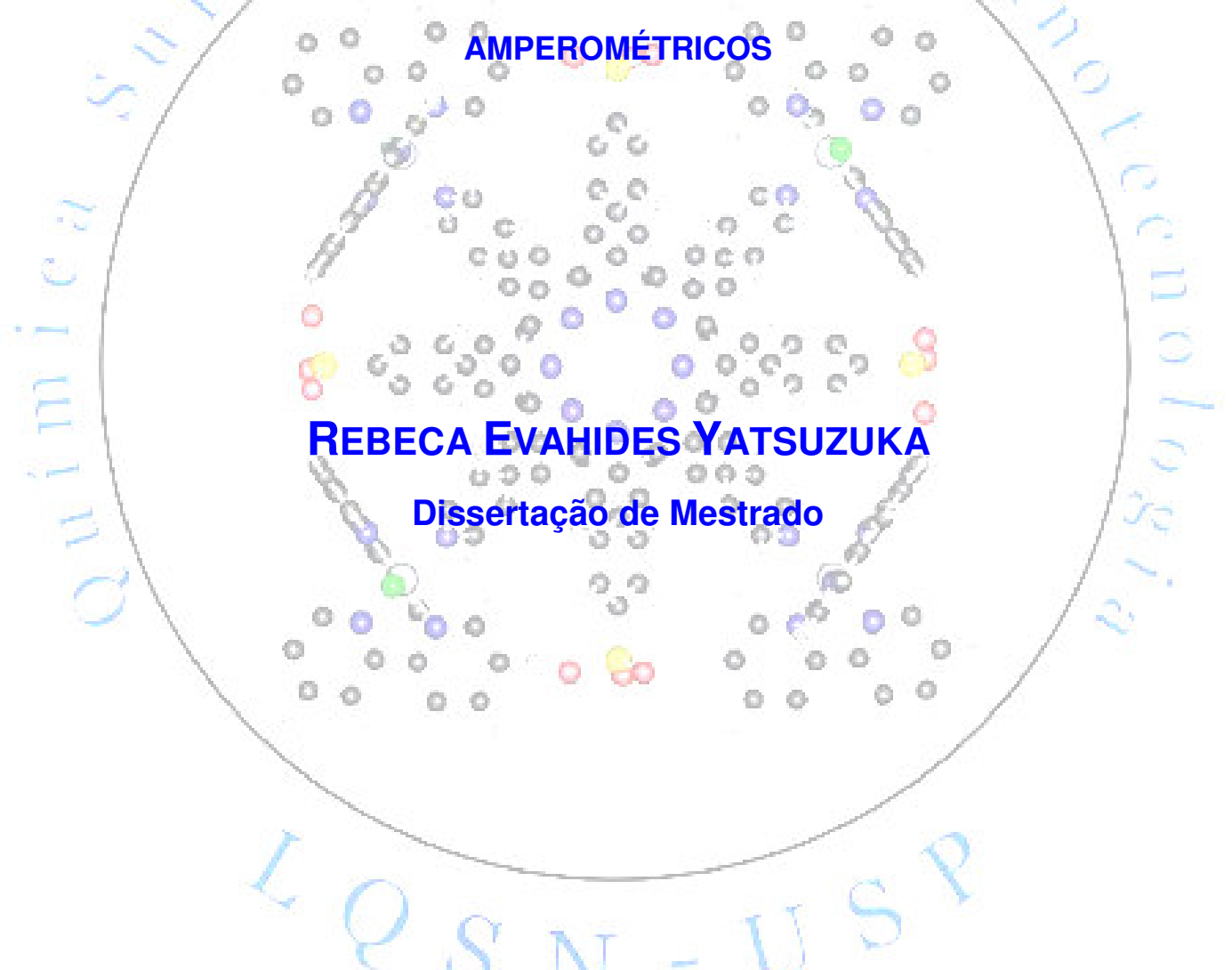

Orientador: Prof. Dr. Koiti Araki

SÃo PAULO

03/09/2007 


\section{REBECA EVAHIDES YATSUZUKA}

NANOMATERIAIS HÍBRIDOS DE PORFIRINAS SUPRAMOLECULARES E NANOPARTÍCULAS DE OURO E SUAS APLICAÇÕES EM DISPOSITIVOS AMPEROMÉTRICOS

Dissertação apresentada ao Instituto de Química da Universidade de São Paulo para obtenção do Título de Mestre em Química (Química Inorgânica)

Orientador: Prof. Dr. Koiti Araki

São Paulo

2007 
Em memória do meu pai Saide (1950 - 2006) e para minha mãe Teresa, pois eles são a base de tudo o que sou hoje.

Para minha irmã, por alegrar minha vida.

Para o Fabio, minha vida, pelo seu amor acima de tudo.

Vocês são as pessoas mais importantes para mim. 


\section{Agradecimentos}

Ao professor Koiti Araki pela orientação, pela oportunidade e principalmente pela enorme paciência e compreensão sempre presentes em todos esses anos de LQSN. Ao professor Henrique Toma pelas colaborações e contribuições.

Ao Juliano Bonacin e André Formiga pelos inúmeros auxílios durante a etapa inicial do projeto.

Ao Luis Fernando Furtado pela contribuição no preparo dos filmes de nanopartículas, pelas inúmeras discussões e pelos diversos bate-papos amigos.

Ao professor Lúcio Angnes, Maria do Socorro Quintino e lldemar Mayer pela colaboração nos trabalhos de eletrocatálise.

A todos aqueles integrantes do grupo que estiveram no laboratório em outros tempos e de alguma maneira contribuíram neste ou em outros trabalhos: Fabio, Fauze, Fran, Genebaldo, Greg, Herbert, Jeferson, Leonardo, Makoto, Pellegrino, Reginaldo, Sergio, Sofia e Vagner.

Às "florzinhas": Daiana pelos cafezinhos e tricôs de nível totalmente científico, Michele pelas dicas do Word e pela descontração nos finais de tarde, e Aline pelas nossas longas conversas e também pelas "estadias" depois de algumas cervejinhas. 
Agradeço imensamente a vocês também pela amizade e carinho, pois somos o "Fantastic Four" $\odot$.

A todos os demais integrantes do grupo LQSN pela convivência alegre no dia a dia: Anamaria, Caterina, Gustavo, Izilda, Jonnatan, Kaique, Marcelo, Marcio, Mayara, Paulo, Ronaldo, Sergio, Silvia, Sonia, Victor Hugo e Vitor Z. E a todos os meus amigos que estiveram presentes na minha vida, seja na descontração, nos momentos de "happy hour", ou nas horas difíceis do dia a dia.

E ao Fabio, $\vee$, por tanta paciência nas horas dos estresses.

E ao CNPq pelo apoio financeiro. 
"Nossas dúvidas são traiçoeiras e nos fazem perder o bem que poderíamos conquistar se não fosse o medo de tentar."

(William Shakespeare)

"O covarde nunca começa, o fracassado nunca termina, o vencedor nunca desiste." (Normam Vicent Peale)

"Não sobrecarregues os teus dias com preocupações desnecessárias, a fim de que não percas a oportunidade de viver com alegria."

(André Luiz) 


\section{Resumo}

Yatsuzuka, R.E., Nanomateriais híbridos de porfirinas supramoleculares e nanopartículas de ouro e suas aplicações em dispositivos amperométricos. 2007. 103p. Dissertação de Mestrado - Programa de Pós-Graduação em Química Inorgânica. Instituto de Química, Universidade de São Paulo, São Paulo.

Sistemas supermoleculares constituídos por compostos porfirínicos apresentam propriedades e aplicações interessantes na área de catálise, sensores molecular, fotoeletroquímica, dentre diversas outras aplicações. Catalisadores mais eficientes e seletivos para a oxidação de substratos orgânicos são de grande interesse tecnológico. Sistemas supramoleculares contendo metaloporfirinas podem ser ainda utilizados como materiais ativos de sensores para diversas substâncias químicas de grande interesse comercial e ambiental. Nanopartículas de ouro podem ser versáteis "blocos de construção" para obtenção de nanomateriais híbridos devido à possibilidade da funcionalização de sua superfície com diversos ligantes com propriedades específicas

Neste trabalho, uma nova série de porfirinas obtidas por montagem coordenativa de quatro complexos dinucleares de carboxilato de ródio (3TPyP-Rh) foi preparada e caracterizada por espectroscopia UV-vis, ressonância magnética nuclear, termogravimetria e voltametria cíclica.

Filmes supramoleculares híbridos obtidos a partir de nanopartículas de ouro reativas e porfirinas (metaloporfirinas e a supermolécula, 3TPyP-Rh) foram preparadas sobre eletrodos de FTO. Esses eletrodos modificados tiveram suas propriedades eletrocatalíticas estudadas, tendo-se em vista a obtenção de novos sensores amperométricos e comprovar a possibilidade de se modificar as propriedades desse tipo de nanomateriais variando-se os ligantes pontes moleculares. 
Os filmes estudados são eletrocataliticamente ativos para a oxidação de substratos de grande interesse comercial, como ácido ascórbico, sulfito e peróxido de hidrogênio.

Palavras-chave: Nanotecnologia, Química supramolecular, Porfirina, Carboxilato de ródio, Nanopartículas de ouro, Eletrocatálise 


\begin{abstract}
Yatsuzuka, R.E., Hybrid nanomateriais of supramolecular porphyrins and gold nanoparticles and its applications in amperometrics devices. 2007. 103p. Masters Thesis - Graduate Program in Chemistry. Instituto de Química, Universidade de São Paulo, São Paulo.
\end{abstract}

\begin{abstract}
Supramolecular systems consisting by porphyrin derivatives present interesting properties and applications in catalysis, molecular sensors, photoelectrochemistry, among many other applications. Supramolecular systems constituted by metalloporphyrins can be explored as active materials of sensors for several chemical substances of commercial and environmental interest. Gold nanoparticles can be versatile "building blocks" for the preparation of hybrid nanomateriais due to possibility of functionalization with diverse ligands with specific
\end{abstract} properties.

In this work, a new series of porphyrins was obtained by coordenative assembly of four acetate complexes of dirhodium (3TPyP-Rh) and characterized by eletronic spectroscopy, nuclear magnetic resonance, termogravimetric analysis and cyclic voltammetry.

FTO electrodes were modified with films of hybrid supramolecular nanomaterials build-up from reactive gold nanoparticles and mesotetrayridylporphyrin derivatives (metaloporphyrins and the supermolecule, 3TPyP$\mathrm{Rh})$. The eletrocatalytic properties were studied aiming the preparation of new amperometrics sensor and to demonstrate the possibility of controlling the properties of this type of nanomateriais by varying the molecular multi-bridge ligands. We found out that the AuNP/metalloporphyrin nanomaterials films are electrochemically and electrocatalytic active for the oxidation of substrates of great commercial interest, as ascorbic acid, sulfite and peroxide of hydrogen.

Keywords: Nanotechnology, Supramolecular chemistry, Porphirin, Carboxilato dirhodium, Eletrocatalysis. 


\section{Lista de Abreviaturas}

AuNP: Nanopartículas de ouro

3TPyP: meso-tetra(3-piridil)porfirina

4TPyP: meso-tetra(4-piridil)porfirina

M-TPyP: meso-tetrapiridilporfirina metalada

3TPyP-Rh: tetrapiridilporfirina coordenada a quatro complexos binucleares de ródio

4-MPy: 4-mercaptopiridina

4,4'- Bipy: 4,4'-bipiridina

3-MPTS: (3-mercapto-propil)trimetoxisilano

VC: Voltamograma Cíclico

FTO: Eletrodo de vidro recoberto com óxido de estanho dopado com flúor

EPH: Eletrodo padrão de hidrogênio

$E_{1 / 2}$ : Potencial de meia onda

$E_{p c}$ : Potencial de pico catódico

$E_{p a}:$ Potencial de pico anódico

DMF: N,N'-dimetilformamida

DCM: Diclorometano

DMSO: Dimetilsulfóxido

TG: Termogravimetria

DTG: Termogravimetria diferencial

$\mathrm{CDCl}_{3}$ : Clorofórmio deuterado

HOMO: Orbital ocupado de maior energia 


\section{Lista de figuras}

Figura 1.1: A: Base estrutural de um anel porfirínico, B: 5,10,15,20-tetra-(4-piridil)porfirina (4TPyP) e C: 5,10,15,20-tetra-(3-piridil)-porfirina (3TPyP)......................23

Figura 1.2: Estrutura em forma de gaiola dos carboxilatos de ródio (II)...................27

Figura 2.1: Estruturas das supermoléculas: A: $\left[R h_{2}(O A c)_{4}\left(H_{2} \mathrm{O}\right)\right]_{4} T 3 P y P$ e $B$ : $\left[\mathrm{Rh}_{2}(\mathrm{OAc})_{4}\left(\mathrm{H}_{2} \mathrm{O}\right)\right]_{4} \mathrm{~T} 4 \mathrm{PyP}$ 39

Figura 2.2: Esquema mostrando o processo de silanização usando (3-mercaptopropil)trimetoxisilano. 44

Figura 2.3: Imagens de microscopia de varredura de eletrodos de FTO modificados com ácido isonicotínico (A) e 3-MPTS (B) .45

Figura 2.4: Esquema do procedimento experimental de obtenção do filme de AuNP (solução A) e 3TPyP (solução B). 47

Figura 2.5: Representação ilustrativa de uma bicamada do filme a ser obtido. 49

Figura 2.6: Acompanhamento do crescimento do filme de 3TPyP/AuNP por espectroscopia UV-vis. 49

Figura 3.1: Espectro eletrônico da A: 4TPyP base livre, concentração $2.10^{-5} \mathrm{M}$ em $\mathrm{CHCl}_{3}$ e B: 3TPyP base livre.

Figura 3.2: Espectro eletrônico do complexo binuclear de ródio em água, concentração $1.10^{-4} \mathrm{M}$ (visualização das bandas 3 e 4 ) e $1.10^{-3} \mathrm{M}$ (visualização das bandas 1 e 2). 52

Figura 3.3: Espectro eletrônico da $\left[\mathrm{Rh}_{2}(\mathrm{OAc})_{4}\left(\mathrm{H}_{2} \mathrm{O}\right)\right]_{4} \mathrm{~T} 3 \mathrm{PyP}$ em $\mathrm{CH}_{2} \mathrm{Cl}_{2}$. 53

Figura 4.1: Comportamento térmico da 3TPyP-Rh e de seus precursores em atmosfera de nitrogênio. .55 
Figura 4.2: Comportamento térmico da 4TPyP-Rh e de seus precursores. .57

Figura 5.1: Espectro de $\mathrm{RMN}$ da $\left[\mathrm{Rh}_{2}(\mathrm{OAc})_{4}\left(\mathrm{H}_{2} \mathrm{O}\right)\right]_{4}$ T3PyP em $\mathrm{CDCl}_{3 .} \ldots \ldots \ldots \ldots \ldots . . . . . . . .59$

Figura 5.2: Espectro $\mathrm{RMN}$ de ${ }^{1} \mathrm{H}$ da $\left[\mathrm{Rh}_{2}(\mathrm{OAc})_{4}\left(\mathrm{H}_{2} \mathrm{O}\right)_{4}\right.$ T4PyP em $\mathrm{CDCl}_{3} \ldots \ldots \ldots \ldots \ldots . . . . . .61$

Figura 6.1: Voltamograma típico da porfirina base livre, 3TPyP em 1,2-dicloroetano, eletrólito suporte $\mathrm{TBAPF}_{6}$ 0,05 M.

Figura 6.2: Voltamograma cíclico do complexo de ródio antes e depois da coordenação de piridina nas posições axiais em 1,2-dicloroetano seco, utilizando como eletrólito suporte $\mathrm{TBAPF}_{6}$ 0,05 M.

64

Figura 6.3: Voltamograma cíclico da $\left[\left\{\mathrm{Rh}_{2}(\mathrm{OAc})_{4}\left(\mathrm{H}_{2} \mathrm{O}\right)\right\}_{4} \mathrm{~T}\right.$ TPyP $]$, em 1,2-dicloroetano, eletrólito suporte $\operatorname{TBAPF}_{6}$ 0,05 M, e velocidade de varredura de $100 \mathrm{mV} / \mathrm{s}$. .66

Figura 7.1: Imagens de microscopia eletrônica de varredura (MEV) do filme de AuNP/4TPyP sobre eletrodos de FTO, com ampliação de 100.000 e 200.000 vezes.

Figura 7.2: VC do eletrodo de FTO modificado pelo filme híbrido de 3TPyP/AuNP, com uma monocamada de acetato de ródio coordenado apenas na última camada, na presença de concentrações crescentes de nitrito. Branco se refere ao voltamograma na ausência de nitrito .75

Figura 7.3: VC dos eletrodos de FTO modificado com filme de (A) Fe3TPyP/AuNP e (B) Co3TPyP/AuNP (10 monocamadas), na presença de concentrações crescentes de nitrito em tampão acetato, $\mathrm{pH} 5$ e velocidade de varredura de $50 \mathrm{mV} / \mathrm{s}$. .77

Figura 7.4: Esquema do filme nanoestruturado a partir de supermolécula de porfirina ródio e AuNP, tendo 4-MPy como ligante ponte .79

Figura 7.5: VC tampão fosfato $(\mathrm{pH} 6,8)$ do eletrodo de A: FTO modificado com filme de supermolécula (3TPyP-Rh) apenas com duas bicamadas e AuNP, B: VC do 
eletrodo de FTO não modificado e C: FTO modificado com filme de supermolécula (3TPyP-Rh) com 10 bicamadas.

.82

Figura 7.6: VC em tampão acetato $(\mathrm{pH}$ 5) do filme 3TPyP/AuNP/Rh (complexo de ródio apenas na última camada) na presença de concentrações crescentes de sulfito, velocidade de varredura de $50 \mathrm{mV} / \mathrm{s}$.

Figura 7.7: VC em tampão acetato ( $\mathrm{pH}$ 5) com concentração crescente de sulfito dos filmes de A: Co3TPyP/AuNP e B: Fe3TPyP/AuNP, velocidade de varredura de 50 $\mathrm{mV} / \mathrm{s}$. .84

Figura 7.8: VC em tampão acetato ( $\mathrm{pH}$ 5) com concentração crescente de ácido ascórbico dos filmes de A: supermolécula 3TPyP-Rh/AuNP e B: AuNP/3TPyP/Rh (com acetato de ródio apenas na última camada), velocidade de varredura de 50 $\mathrm{mV} / \mathrm{s}$. .86

Figura 7.9: Voltamogramas cíclicos em tampão fosfato, pH 6,8, com concentrações crescentes de ácido ascórbico utilizando um eletrodo limpo de FTO, velocidade de varredura de $100 \mathrm{mV} / \mathrm{s}$. .88

Figura 7.10: VC em tampão acetato $(\mathrm{pH}$ 5) com concentração crescente de ácido ascórbico dos filmes de A: CoTPyP/AuNP e B: FeTPyP/AuNP e velocidade de varredura de $50 \mathrm{mV} / \mathrm{s}$. .89

Figura 7.11: VC em tampão acetato ( $\mathrm{pH}$ 5) em concentração crescente de peróxido de hidrogênio dos filmes de A: Co3TPyP/AuNP e B: Fe3TPyP/AuNP, velocidade de varredura de $50 \mathrm{mV} / \mathrm{s}$. 91

Figura 7.12: Voltamogramas cíclicos tampão acetato $(\mathrm{pH}$ 5) do filme de 3TPyP/AuNP/Rh na presença de concentração crescente de peróxido de hidrogênio, velocidade de varredura de $50 \mathrm{mV} / \mathrm{s}$. 93 


\section{Sumário}

1. INTRODUÇÃO

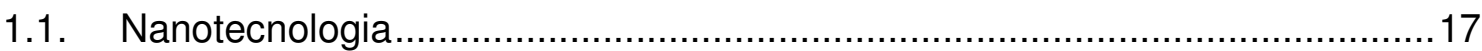

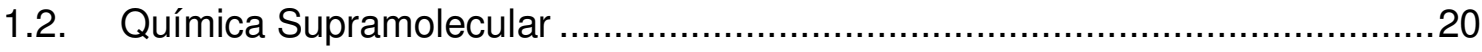

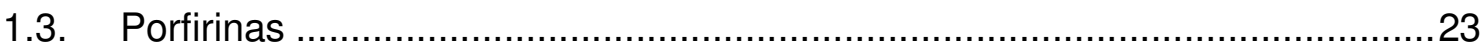

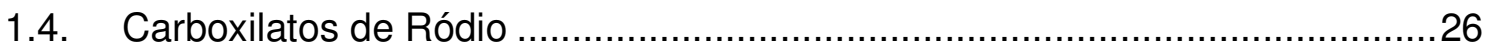

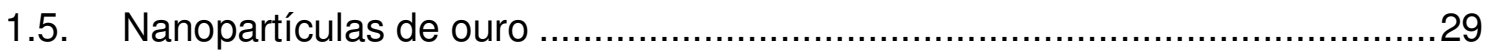

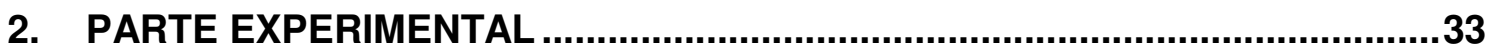

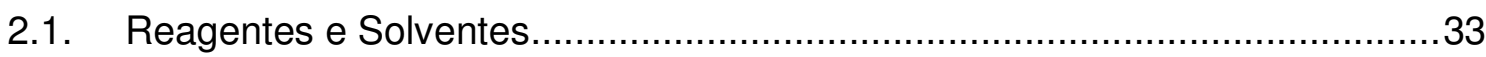

2.2. Procedimentos e Equipamentos ............................................................

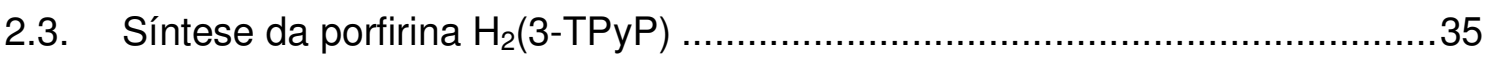

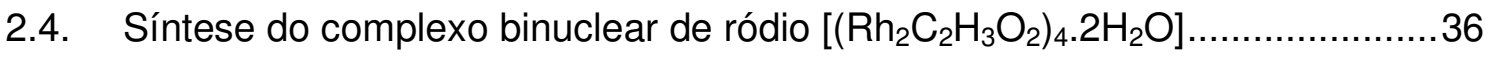

2.5. Síntese das Porfirinas Supermoleculares..................................................37

2.6. Síntese das Nanopartículas de ouro.......................................................

2.7. Modificação dos eletrodos: produção dos filmes nanoestruturados ................42

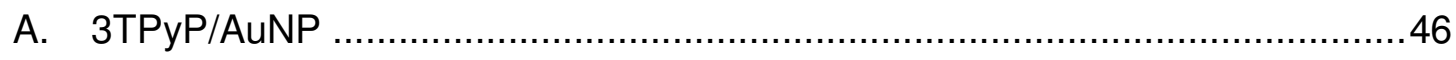

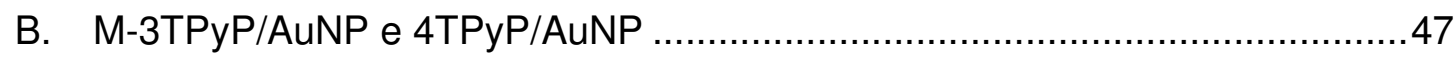




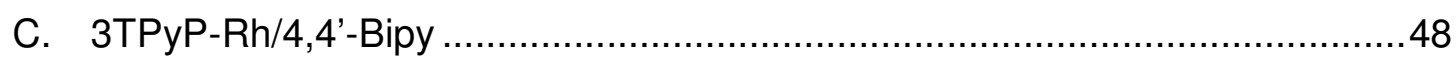

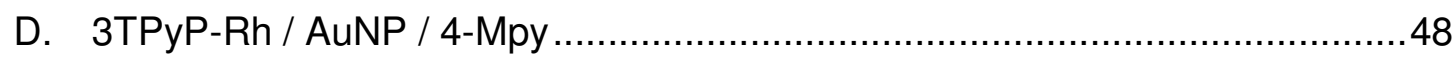

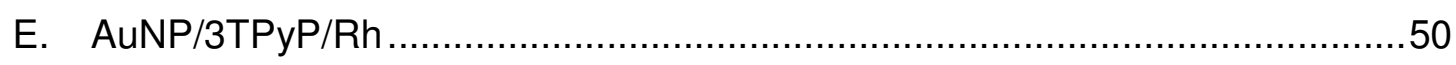

3. ESPECTROSCOPIA ELETRÔNICA.......................................................51

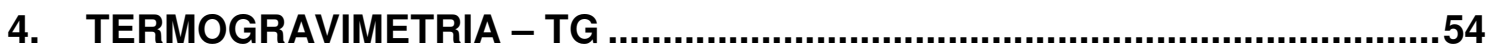

5. RESSONÂNCIA MAGNÉTICA NUCLEAR - RMN .....................................58

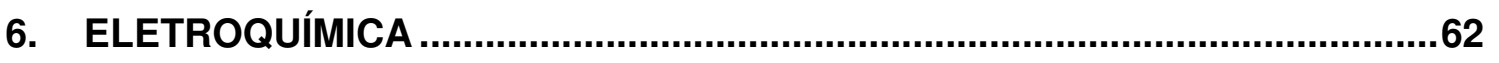

7. ESTUDOS ELETROCATALÍTICOS COM FILMES HÍBRIDOS DE PORFIRINAS SUPRAMOLECULARES E NANOPARTÍCULAS DE OURO................................67

7.1. Oxidação eletrocatalítica de nitrito ............................................................

7.2. Oxidação eletrocatalítica de sulfito ……………......................................

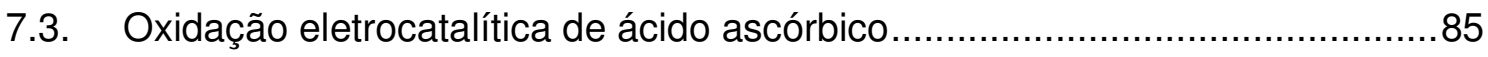

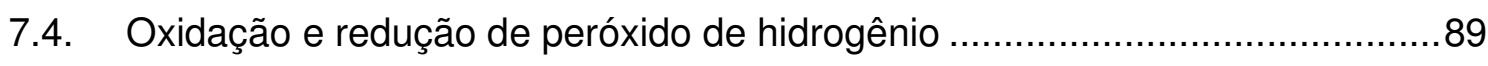

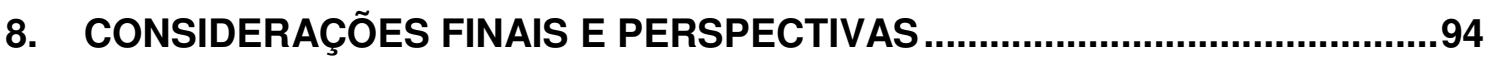

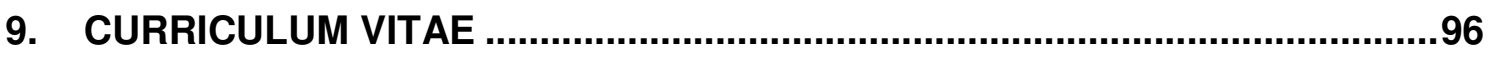

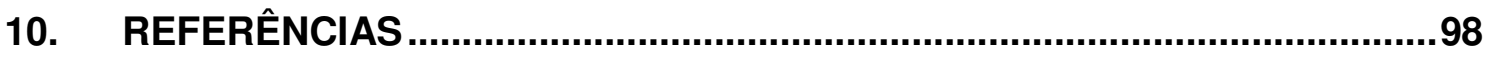




\section{Introdução}

\subsection{Nanotecnologia}

A nanociência é uma área emergente da ciência que trata do estudo de materiais que têm dimensões extremamente reduzidas. A nanotecnologia se refere à preparação de materiais, dispositivos ou processos que envolvam o controle da matéria na escala do bilionésimo do metro. Essa unidade é expressa pelo termo nano, e é um prefixo grego que significa "anão". De fato, convencionou-se que a faixa de interesse e da nanociência e da nanotecnologia se encontra em materiais ou estruturas com dimensões na faixa de cerca de 1 a 100 nanômetros (nm). O limite inferior é definido pela escala atômica/molecular. Assim, a nanotecnologia implica em nanomateriais, ou seja, materiais funcionais que apresentem tamanhos na escala nanométrica.

Os fundamentos da nanotecnologia foram propostos pelo físico norteamericano Richard Feynman em uma conferência proferida em 1959 com o título "There's Plenty of Room at the Bottom". Nessa palestra Feynman começou a discussão do tema mostrando as possibilidades de miniaturização e terminou com uma exploração do que poderia se obter a partir do controle dos materiais, átomo por átomo.

Porém, avanços significativos na nanotecnologia não foram notados até o início dos anos 80, devido à falta de novos instrumentos que permitissem a 
visualização (caracterização) e manipulação dos átomos proposta por Feynmam. Atualmente é possível esse tipo de manipulação através dos novos microscópios de tunelamento (STM), que permitem medir e manipular materiais na escala nanométrica. Contudo, o comportamento desses materiais obedece a leis físicas bastante diferentes daquelas com as quais estamos acostumados em macro-escala.

O objetivo da nanotecnologia, seguindo a proposta de Feynman, é o de criar novos materiais e desenvolver novos produtos e processos baseados na crescente capacidade da tecnologia moderna de ver e manipular átomos e moléculas.

Em 1981, Eric Drexler publicou o primeiro artigo em nanotecnologia molecular intitulado "Molecular engineering: An approach to the development of general capabilities for molecular manipulation" [1]. Nesse artigo o autor propõe novos métodos para síntese de proteínas como parte da estratégia de desenvolver novos e avançados dispositivos moleculares montados átomo por átomo.

A nanociência e a nanotecnologia têm como base dois conceitos distintos que são chamados de top-down (de cima para baixo) e bottom-up (de baixo para cima). A primeira abordagem consiste na miniaturização dos materiais e estruturas da escala micro para a escala nano. Esse tipo de abordagem exige o domínio de toda tecnologia da microeletrônica, implicando no aprimoramento de um vasto arsenal de recursos e mão de obra muito qualificada. Acredita-se que esta abordagem vá encontrar uma barreira intransponível para o avanço da microeletrônica, pois as propriedadades dos semicondutores passam a ser influenciados pela diminuição de tamanho das estruturas a partir de um tamanho limite. Isto se deve ao fato delas 
serem definidas coletivamente pela interação entre os átomos nos materiais, formando estruturas de bandas. Além disso, os investimentos necessários para efetuar os processos litográficos vão se tornando cada vez maiores à medida que as estruturas decrescem de tamanho na escala nanométrica, podendo chegar a inviabilizá-los economicamente.

A segunda abordagem se baseia na construção de nanoestruturas e nanomateriais a partir dos átomos e das moléculas, por meio de processos que permitam o controle tridimensional, gerando sistemas cada vez mais complexos. Para tal finalidade podem ser utilizadas estruturas orgânicas e inorgânicas menores $^{[2]}$, que serviriam como blocos de construção dos nanomateriais e das nanoestruturas. Assim, acredita-se que a estratégia "bottom-up", também denominada nanotecnologia molecular, vá resolver aqueles problemas pois novos métodos e técnicas de manipulação molecular ou de auto-montagem (self-assembly) podem ser desenvolvidos.

A nanotecnologia, criada a partir dos fundamentos desenvolvidos pela nanociência, oferece perspectivas muito amplas e a promessa de criação de produtos inovadores, capazes de transformar e mesmo redefinir várias indústrias. Essa nova ciência permitirá a criação de materiais, equipamentos e sistemas através do controle da matéria na escala nanométrica. 


\subsection{Química Supramolecular}

A expressão Química Supramolecular foi cunhada em 1969 por Jean-Marie Lehn ${ }^{[3,4]}$, em seu estudo de compostos de inclusão e criptandos. A outorga do Prêmio Nobel de Química de 1987, a Charles Pedersen, Donald Cram e Jean-Marie Lehn significou o reconhecimento dessa estratégia inovadora pela comunicade científica e a disseminação da mesma na comunidade química. Lehn definiu a Química Supramolecular ${ }^{[5,6]}$ como a "química da ligação intermolecular" no seu sentido mais amplo. Do mesmo modo que moléculas são construídas conectando-se átomos através de ligações covalentes, compostos supermoleculares são construídos ligando-se moléculas. Assim, a química supramolecular pode ser entendida como a "química além da molécula". Enquanto que a "química molecular" é a química da ligação covalente, visando o controle das regras que regem as ligações, estruturas e propriedades de espécies moleculares, a química supramolecular focaliza a compreensão dos fenômenos de interação em entidades organizadas, geradas por meio da associação de duas ou mais unidades moleculares. Essas unidades podem se associar através de ligações covalentes, forças eletrostáticas ou ainda interações de Van der Waals, de modo que as propriedades eletrônicas das subunidades sejam apenas perturbadas.

Sistemas supramoleculares também podem ser obtidos por automontagem através, por exemplo, de ligações coordenativas metal-ligante. Uma das principais virtudes dos sistemas obtidos dessa maneira é que estes não apresentam necessariamente as propriedades das suas moléculas integrantes, mas podem e 
tendem a apresentar características únicas, ou seja, os sistemas supramoleculares não representam necessariamente a soma direta das propriedades das moléculas integrantes, mas tendem a adquirir propriedades sinérgicas, típicas do sistema como um todo.

Devido à grande variedade de elementos metálicos que podem ser associados aos sistemas supramoleculares, pode-se ter controle das propriedades redox, catalíticas, eletrocatalíticas e eletrônicas das estruturas de interesse. Tendose o controle dessas propriedades, que podem ser largamente exploradas, é possível propiciar a ocorrência de fenômenos ou atividades não observadas em moléculas simples como, por exemplo, o reconhecimento molecular e a ativação de catalisadores para processos multieletrônicos. Dessa maneira, as supermoléculas podem ser conceituadas como espécies inteligentes, capazes de compreender e responder a sinais químicos, executando funções através de interações moleculares.

Exemplos característicos de estruturas supramoleculares são encontrados em abundância nos sistemas biológicos. Nesses sistemas, as transformações ocorrem de forma seqüencial através do encadeamento e organização das biomoléculas, geralmente dispostas em membranas ou grandes estruturas protéicas, as quais proporcionam o arranjo supramolecular necessário para a ocorrência das transformações com alta especificidade e eficiência. Um exemplo típico é o mecanismo da fotossíntese, onde a energia solar é transformada em energia química através de uma seqüência complexa de eventos nos centros reacionais. 
Um dos aspectos fundamentais para o desenvolvimento da química supramolecular é o domínio e aplicação dos fundamentos do reconhecimento molecular. Nesse sentido, por exemplo, tem sido dado destaque à importância das ligações formadas serem relativamente lábeis. Essa característica é fundamental para que as ligações individuais possam se formar e quebrar mais ou menos rapidamente, até alcançar a situação de menor energia. Uma alta seletividade pode ser conseguida lançando-se mão, não apenas de uma, mas de múltiplas interações concomitantes. Isso faz com que as estruturas supramoleculares com reconhecimento molecular, sejam capazes de montar-se, corrigir-se e regenerar-se espontaneamente. Pode-se citar como exemplos a formação de micelas, vesículas e membranas, a partir de substâncias anfifílicas apropriadas. Essa organização molecular associada à formação de unidades mais complexas pode levar à sistemas químicos inteligentes, dotados de capacidade de comunicação, reconhecimento molecular, transporte de energia e de elétrons ${ }^{[6,7,8,9,10,11]}$.

O reconhecimento molecular pode ser representado pelo modelo de chave fechadura, proposto por Emil Fischer em 1894, em que a interação de uma enzima com seu substrato se dá do mesmo modo que uma chave com a sua fechadura (lock and key). O reconhecimento implica que a geometria e as interações não-covalentes sejam compatíveis entre as estruturas interagentes. Uma das motivações da Química Supramolecular está em desenhar sistemas químicos que mimetizem processos biológicos, ou seja, os sistemas biológicos são modelos que servem de 
inspiração para o desenvolvimento da química e de novos sistemas supramoleculares.

\subsection{Porfirinas}

As porfirinas são complexos macrocíclicos que estão bastante presentes na natureza, onde desempenham uma grande variedade de funções biológicas. Esses complexos formam o núcleo prostético de muitas metaloproteínas. Pode-se citar como exemplo o citocromo C (atuando como transportadores de elétrons), mioglobina e hemoglobina (transporte de oxigênio e gás carbônico). Atuam também na catalase e peroxidases, catalisando a decomposição do peróxido de hidrogênio gerado no organismo, entre outras diversas funções.

A união de quatro anéis pirrólicos por uma ponte $-\mathrm{CH}$ pelas posições $\alpha$ (representada pelas ligações de números $(1,4,6,9,11,14,16,19)$, é a base estrutural de uma porfirina, como mostrado na Figura 1.1A abaixo.
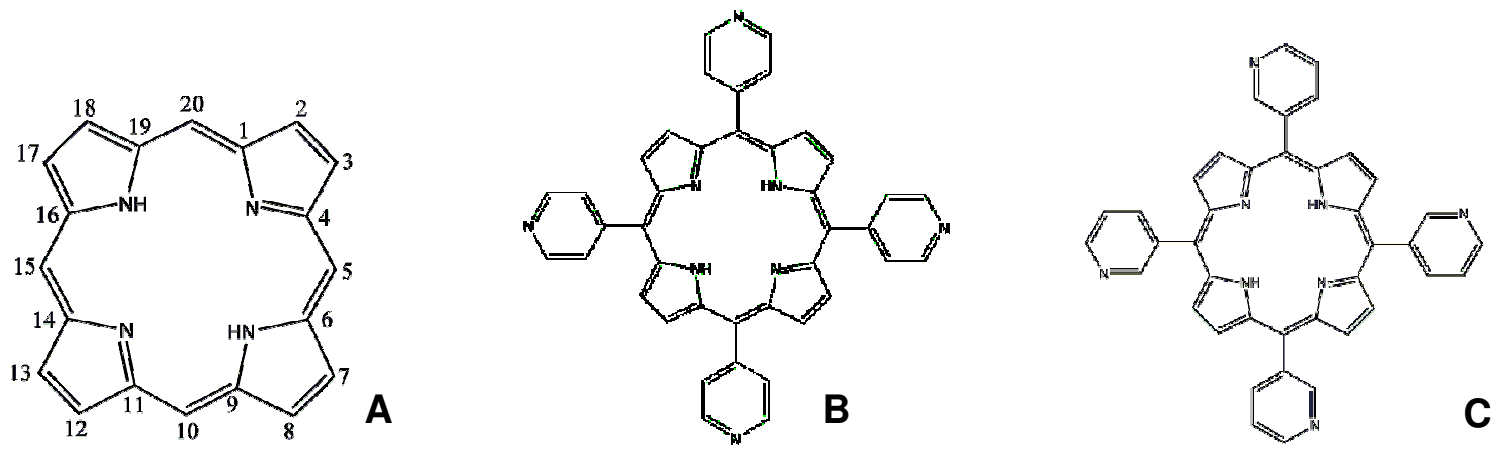

Figura 1.1: A: Base estrutural de um anel porfirínico, B: 5,10,15,20-tetra-(4-piridil)-porfirina (4TPyP) e C: 5,10,15,20-tetra-(3-piridil)-porfirina (3TPyP). 
A estrutura macrocíclica da porfirina foi proposta pela primeira vez por Küster em 1912, mas foi só no ano de 1929 que Fischer obteve sucesso na síntese a partir de pirrol.

A porfirina é uma substância anfótera, pois existem dois nitrogênios protonados e dois livres no anel porfirínico da base livre, como pode ser observado na Figura 1.1. Assim, os dois prótons podem ser removidos gerando o diânion ou adicionados gerando o dicátion. As propriedades ácido-base das porfirinas podem então ser influenciadas pelos grupamentos substituintes presentes no anel.

Os derivados porfirínicos têm coloração intensa, apresentando espectros de absorção característicos, com uma banda de absorção intensa em torno de 420 nm, chamada de banda Soret, e outras quatro de menores intensidades denominadas bandas Q. Variações dos substituintes periféricos podem causar mudanças na intensidade e no comprimento de onda das bandas, porém as substituições dos hidrogênios pirrólicos ou dos hidrogênios dos grupos metino causam efeitos mínimos sobre os espectros eletrônicos se não ocorrer interações entre os substituintes e o sistema m conjugado do anel.

Uma das principais características das porfirinas reside no fato delas coordenarem íons metálicos, que podem fazer o papel de centros ativos em diversos processos catalíticos, eletrocatalíticos e de transferência de carga. Este sítio é responsável pelas diferentes funções que as porfirinas podem exercer nas mais diversas atividades, como transporte, reconhecimento, catálise entre outras muitas. 
Nos modelos sintéticos, na maioria dos casos, a porfirina é projetada para mimetizar sítios catalíticos biológicos, como por exemplo, o grupo heme (encontrado na hemoglobina, mioglobina e citocromos) e a clorofila. Este último é um composto dihidroporfirínico de magnésio que, em conjunto com outras espécies, absorve intensamente a luz ou a energia de um sistema de moléculas, ativando-o para reações de transferência e separação de elétrons.

Outra característica de grande relevância compostos moleculares e em particular das porfirinas reside no fato de ser possível a transferência das propriedades dos mesmos para a superfície de um eletrodo por meio da deposição organizada e controlada do material. Desse modo é possível a obtenção de filmes das mais diversas espessuras desejadas e seu uso em várias aplicações, como por exemplo, em interfaces de dispositivos moleculares para sensoriamento.

No nosso Grupo, o estudo específico das supermoléculas obtidas pela coordenação de quatro complexos de rutênio às 5,10,15,20-tetra(4-piridil)porfirinas, M-4-TPyP, foram iniciadas em 1987. Assim, as primeiras porfirinas supermoleculares foram obtidas pela coordenação de grupos $\left[\mathrm{Ru}(\text { edta) }]^{-}\right.$e $\left[\mathrm{Ru}\left(\mathrm{NH}_{3}\right)_{5}\right]^{2+}$, com o intuito

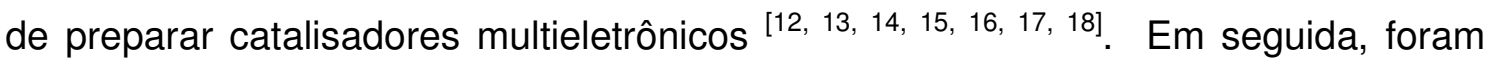
estudadas as porfirinas supermoleculares ${ }^{[19,20,21,22,23,24,25,26,27,28,29,30,31]}$ obtida pela coordenação de quatro grupos $\left[\mathrm{Ru}(\text { bipy })_{2} \mathrm{Cl}\right]^{+}$às $\mathrm{M}-\mathrm{TPyPs}$. Com essa série de compostos, foram estudados os efeitos da interação entre o anel porfirínico e os complexos de rutênio periféricos sobre as propriedades espectroscópicas, eletroquímicas e fotofísicas. Além disso, vários estudos sobre propriedades 
catalíticas, eletrocatalíticas, de condução e fotocatalíticas de porfirinas tetrarutenadas têm sido realizados pelo nosso grupo ${ }^{[32]}$.

Os filmes obtidos a partir destes compostos apresentaram elevada atividade eletrocatalítica para a oxidação de diversos substratos. Eletrodos modificados com estes materiais foram utilizados como interfaces em sensores amperométricos para a análise de substratos de interesse biológico, ambiental e também comercial tais como sulfito, nitrito, ácido ascórbico, $\mathrm{NADH}$, dopamina e glicose. Além disso, estes eletrodos recobertos por porfirinas apresentam alta sensibilidade e estabilidade.

Nosso interesse nesse trabalho está voltado, em especial, aos sistemas supramoleculares baseados em porfirinas, mais especificamente as tetrapiridilporfirinas (TPyP), Figura 1.1B, uma vez que, a partir deste composto macrocíclico, é possível a obtenção de diversos sistemas estruturalmente bem definidos e com alto nível de organização.

\subsection{Carboxilatos de Ródio}

A pesquisa com dímeros de ródio vem trazendo vários aspectos interessantes como, por exemplo, a obtenção de eficientes catalisadores para sínteses orgânicas. Uma grande quantidade de exemplos de aplicações desses compostos com as mais diversas finalidades tais como a hidrogenação de alcenos ou o uso como agente antitumoral ${ }^{[33]}$ podem ser encontradas na literatura. Além do mais, os carboxilatos 
de ródio são potentes inibidores de enzimas que apresentam grupamentos sulfidrilas próximos ao sítio ativo.

Os carboxilatos de ródio possuem dois átomos de Rh no estado de oxidação +2 que estão unidos por uma ligação simples metal-metal e por quatro ligantesponte acetato nas posições equatoriais, fazendo com que a estrutura apresente formato de gaiola, como pode ser visto na Figura 1.2. A estrutura do tipo gaiola é bastante estável e reações onde há a troca dos ligantes equatoriais só ocorrem em condições especiais de alta energia ${ }^{[34]}$. Os ligantes coordenados nas posições axiais são lábeis e podem ser facilmente substituídos. Assim, pode haver a coordenação reversível de vários ligantes ou moléculas de solvente, formando adutos de interesse. Essa posição pode portanto ser facilmente ocupada por diversos tipos de moléculas que contenham átomos doadores de elétrons, sendo uma das características responsáveis pela atividade catalítica e antitumoral desses compostos.

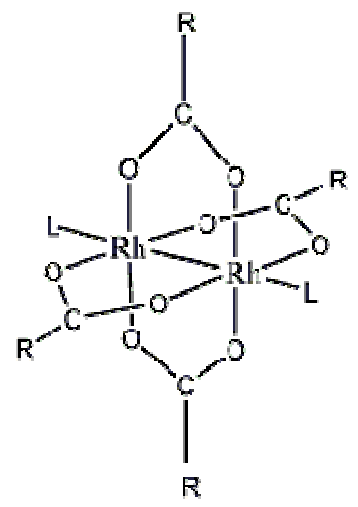

Figura 1.2: Estrutura em forma de gaiola dos carboxilatos de ródio (II). 
O acetato de ródio (II) é solúvel em uma grande variedade de solventes, incluindo água, THF (tetrahidrofurano), etanol, acetona, ácido acético, acetonitrila, DMSO (dimetilsulfóxido), nitrometano e trietilfosfato. Acredita-se que as posições terminais na esfera de coordenação sejam ocupadas por moléculas de solvente, embora muitos dos adutos não sejam suficientemente estáveis para existir em estado sólido a temperatura ambiente.

O processo de troca de ligantes é geralmente acompanhado por mudança de cor da solução, sendo que em solução aquosa o complexo apresenta cor verde. A cor dos carboxilatos depende da natureza do átomo doador dos ligantes axiais. Compostos verdes ou azuis denotam adutos associados com ligantes coordenados por átomos de $\mathrm{C}$ ou $\mathrm{O}$, vermelhos ou róseos sugerem ligações através do $\mathrm{Ne}$ alaranjados ou violáceos indicam ligações por átomos de $\mathrm{S}$ ou $\mathrm{P}$. Por exemplo, quando uma ou duas moléculas de água que estão coordenadas às posições axiais são trocadas por um ligante que contenha um átomo de nitrogênio, a cor do complexo muda de verde para rosa. Pode-se usar essa propriedade para se monitorar diretamente a concentração e a velocidade de troca dos ligantes usando técnicas espectrofotométricas.

Os carboxilatos de ródio em geral são neutros, diamagnéticos e cineticamente estáveis a temperatura ambiente, quando se trata da troca dos carboxilatos (e não dos ligantes axiais). As quatro pontes carboxilato que ocupam as posições equatoriais são cineticamente inertes, contrastando com as posições axiais, que trocam o ligante rapidamente. Vários estudos ${ }^{[35,36,37]}$ têm descrito as propriedades 
termodinâmicas e cinéticas das ligações axiais em complexos do tipo $\left[R h_{2}(O C R)_{4}\right]$, sugerindo algumas tendências interessantes. A formação do aduto é um processo em duas etapas, formando em primeiro lugar um complexo 1:1 e finalmente um complexo 2:1. Uma avaliação das constantes de formação das duas etapas revela consistentemente que uma vez formado o aduto 1:1, o segundo ligante apresenta uma dificuldade bem maior em se ligar ao segundo átomo de ródio. De fato, as ligações formadas entre o ródio e os ligantes axiais nos carboxilatos diméricos são fracas se comparadas às ligações Rh-L ou Rh-X em complexos mononucleares, sendo este comportamento atribuído à influência trans da ligação sigma Rh-Rh.

Os carboxilatos de Rh são tipicamente ácidos intermediários de Lewis, que tendem a formar ligações axiais mais fortes com ligantes $\pi$ receptores, como por exemplo, a piridina. Contudo, a ligação axial do Rh é compreendida como sendo essencialmente de natureza $\sigma$, que entretanto é realçada pela interação $\pi$ com os ligantes axiais. Assim, a força da ligação com a piridina é significativamente aumentada devido às interações $\pi$.

\subsection{Nanopartículas de ouro}

As nanopartículas são sistemas de grande interesse na nanociência e na nanotecnologia devido à sua grande versatilidade e funcionalidade. Do ponto de vista tecnológico, as nanopartículas podem ter suas superfícies modificadas com

moléculas de interesse ou polímeros, fato esse que amplia imensamente suas 
aplicações. Por exemplo, as nanopartículas podem ser utilizadas em sensoriamento químico ou biológico, bastando modificá-las com espécies que reconhecem outros grupos complementares, como no caso da interação antígeno-anticorpo. Nanopartículas de materiais semicondutores, por exemplo, seleneto de cádmio (CdSe) e sulfeto de zinco (ZnS) estão sendo utilizadas como marcadores biológicos fluorescentes em função de sua maior estabilidade em relação aos corantes orgânicos tradicionais ${ }^{[38]}$.

Tais características podem ser aproveitadas para a obtenção de uma grande variedade de nanomateriais $s$ e o desenvolvimento de dispositivos. As partículas nanométricas ( 1-100 nm de diâmetro) têm atraído grande atenção devido às novas propriedades físicas e químicas originadas pela sua elevada relação superfície volume. Uma propriedade diretamente relacionada com a diminuição do tamanho das partículas é o aumento da sua área superficial, o que melhora a sua eficiência em aplicações que sejam dependentes de sítios superficiais, como por exemplo as propriedades catalíticas. Logo, as nanopartículas proporcionam uma maior quantidade de átomos ou sítios ativos na superfície, intensificando assim a atividade catalítica ou de absorção, por exemplo.

Recentemente foi publicado um número especial da revista Scientific American (setembro de 2001), totalmente dedicado à nanotecnologia, que aponta algumas aplicações comerciais em catálise (ExxonMobil), armazenagem de dados (IBM), liberação de drogas (Gilead Sciences), manufatura de matérias-primas 
(Carbon Nanotechnologies) e melhoria de materiais convencionais (Nanophase Technologies), entre outras.

Cientificamente, o começo da química do ouro nanoparticulado se deu em meados do século XIX, mais precisamente em 1857, quando Michael Faraday ${ }^{[39]}$ gerou ouro coloidal pela primeira vez, reduzindo $\mathrm{AuCl}_{4}{ }_{4}^{-}$com fósforo branco em $\mathrm{CS}_{2}$, formando uma solução coloidal de cor vermelha intensa.

Dependendo da estratégia sintética que se utiliza para a obtenção das nanopartículas, é possível ter controle de algumas características como por exemplo tamanho de partícula, grau de dispersão e principalmente funcionalização de sua superfície. Tendo-se a posse do controle dessas características é possível manipular funções específicas, lembrando que as nanopartículas metálicas possuem propriedades físicas e químicas dependentes do seu tamanho. Dentre as propriedades diferenciadas destacam-se as ópticas, magnéticas e catalíticas. As nanopartículas apresentam ainda propriedades intermediárias entre aglomerados metálicos (clusters) e estruturas moleculares.

A redução do tamanho das partículas de ouro para a escala nanométrica é responsável por alterações consideráveis em propriedades fundamentais do ouro metálico, como a cor. Portanto, as nanopartículas de ouro podem assumir diferentes cores conforme o seu tamanho. O ouro nanoparticulado quando em solução apresenta intensa coloração avermelhada, vinho ou arrocheada, contrastando com o ouro metálico amarelo. Assim, a investigação das propriedades eletrônicas das nanopartículas de ouro pode ser feita por espectroscopia eletrônica UV-vis. Nesses 
nanomateriais, os elétrons superficiais (plasmons) estão distribuídos em estruturas de bandas com energias distintas. Desse modo, a cor das nanopartículas depende da densidade de estados eletrônicos e do tamanho das nanopartículas, pois quando a onda eletromagnética interage com as mesmas gera um movimento ondulatório ressonante dos elétrons superficiais, cuja freqüência depende daquelas propriedades físicas. As nanopartículas de ouro com tamanhos de cerca de 3 a 30 $\mathrm{nm}$ se caracterizam por uma banda de plasmon com absorvidade máxima em aproximadamente $520 \mathrm{~nm}$.

A escala nanométrica é especialmente interessante para a química supramolecular por fazer a interface entre a escala molecular $(\AA ̊ \AA)$ da mecânica quântica e a escala macroscópica da eletrodinâmica clássica ( $\mu \mathrm{m})$. 


\section{Parte experimental}

\subsection{Reagentes e Solventes}

Os solventes utilizados nas sínteses tanto dos elementos precursores quanto das supermoléculas foram obtidos da Merck ou da Aldrich. Solventes utilizados em experimentos foram devidamente destilados e tratados com secantes ou peneiras moleculares para a remoção de água. A água utilizada nos experimentos e nas soluções aquosas foi destilada em sistema Millipore Milli-Q, $R=20 \mathrm{M} \Omega$.

Todos os reagentes utilizados foram de grau analítico e sem tratamento prévio, a não ser quando especificado.

\subsection{Procedimentos e Equipamentos}

Os estudos de espectroscopia UV-Vis foram efetuados em um espectrofotômetro de matriz de diodos HP8453A na faixa de 190 a 1100 nm.

As análises estruturais por espectroscopia de ressonância magnética nuclear (RMN) de prótons foram realizadas num espectrofotômetro Varian Inova Unit 300 MHz da central analítica do IQ-USP. As microanálises também foram realizadas pela central analítica do instituto de Química.

Os dados de termogravimetria foram obtidos num instrumento da Shimadzu modelo TGA50 e/ou DTA-50, usando uma velocidade de aquecimento de $10 \stackrel{\circ}{\mathrm{C}}$ por 
minuto, sob fluxo constante ( $50 \mathrm{~mL} / \mathrm{min})$ de gás nitrogênio ou ar sintético. As curvas obtidas foram realizadas na faixa de temperatura de 20 a $900^{\circ} \mathrm{C}$, utilizando-se um cadinho de platina contendo aproximadamente $4 \mathrm{mg}$ de amostra.

Os voltamogramas cíclicos foram obtidos utilizando-se um potenciostato/galvanostato da Autolab, modelo PGSTAT 30, acoplado a um microcomputador. A cela eletroquímica utilizada foi a convencional de três eletrodos: eletrodo de trabalho (disco de platina), eletrodo de referência (fio de platina imerso em solução de $\mathrm{AgNO}_{3}$ 0,01M / TEAClO 4 0,1 M em acetonitrila) e eletrodo auxiliar (fio de platina helicoidal). Os experimentos foram realizados em 1,2-dicloroetano seco, utilizando como eletrólito suporte $\mathrm{TBAPF}_{6}$ 0,05M. Todos os potenciais foram referenciados em relação ao eletrodo padrão de hidrogênio (EPH) somando-se $0,503 \mathrm{~V}$ aos valores obtidos em relação ao eletrodo de referência experimental.

Os estudos eletrocatalíticos dos filmes de porfirinas e AuNps montados sobre FTO foram realizados utilizando-se o mesmo arranjo experimental utilizado nas voltametrias, porém o eletrólito suporte empregado para as medidas foi $\mathrm{KNO}_{3}(0,5$ M) em tampão acetato $\mathrm{pH} \mathrm{5,0} \mathrm{ou} \mathrm{tampão} \mathrm{fosfato} \mathrm{pH} 6,8$. Nesse caso foram empregados eletrodos de FTO modificados como eletrodo de trabalho.

Os estudos de crescimento dos filmes híbridos orgânico-inorgânico contendo nanopartículas de ouro foram acompanhados por espectroscopia UV-Vis, utilizandose o espectrofotômetro HP8453. Os estudos de morfologia dos filmes e verificação do tamanho e integridade das AuNPs foram realizados utilizando-se o microscópio 
eletrônico de varredura (MEV) da Jeol, modelo JSM7401F, da Central Analítica do Instituto de Química.

\subsection{Síntese da porfirina $\mathrm{H}_{2}(3-\mathrm{TPy})$}

Para a síntese da 3-TPyP, $15 \mathrm{~mL}$ de 3-piridil-carboxaldeído foram dissolvidos em $700 \mathrm{~mL}$ de ácido acético glacial e $10 \mathrm{~mL}$ de pirrol foram adicionados lentamente àquela solução. Em seguida, a mistura reacional foi mantida sob refluxo e agitação durante 1 hora, até a solução adquirir coloração violeta. A reação foi acompanhada por espectrofotometria UV-vis e interrompida no momento em que não mais se percebeu mudanças no perfil espectral, que apresentava as bandas características da porfirina. A mistura reacional foi deixada em repouso até atingir a temperatura ambiente e o solvente foi removido no evaporador rotatório. Uma mistura de DMF/Etanol 1:9 foi adicionada ao resíduo e a suspensão filtrada num funil de placa sinterizada. Apenas resquícios das bandas características da 3TPyP foram encontrados no espectro do filtrado, comprovando a quase total ausência de porfirina e a eficiência dessa etapa de separação. A purificação foi realizada por cromatografia em coluna de sílica usando como eluente DCM/Etanol 9:1. O solvente foi removido no evaporador rotatório e o sólido violeta obtido foi deixado num dessecador sob alto vácuo. O rendimento da reação foi de aproximadamente $20 \%$, sendo compatível com o método empregado. Geralmente os rendimentos deste tipo 
de reação de ciclização são baixos devido à ocorrência de reações paralelas competitivas de polimerização mais efetivas.

\subsection{Síntese do complexo binuclear de ródio $\left[\left(\mathrm{Rh}_{2} \mathrm{C}_{2} \mathrm{H}_{3} \mathrm{O}_{2}\right)_{4} \cdot 2 \mathrm{H}_{2} \mathrm{O}\right]$}

A síntese do composto dinuclear de ródio contendo quatro ligantes carboxilatos em ponte já é conhecida e está bem estabelecida na literatura ${ }^{[40]}$. Os pioneiros dessa síntese foram Nazarova e colaboradores ${ }^{[41]}$, que obtiveram o composto através da reação de $\mathrm{RhCl}_{3}$ em um mistura de água/etanol com $\left(\mathrm{NH}_{4}\right)_{3} \mathrm{RhCl}_{6}$ em ácido acético. Atualmente utiliza-se outro método que consiste no refluxo de $\mathrm{RhCl}_{3}$ em uma mistura alcoólica de acido acético e acetato de sódio, proposto por Rempel e colaboradores ${ }^{[42]}$, sendo este método o utilizado para a obtenção do composto. Partiu-se de 5,0033g (22,01 mols) de $\mathrm{RhCl}_{3}, 125 \mathrm{~mL}$ ácido acético e $10 \mathrm{~g}$ de acetato de sódio, sendo que a mistura reacional foi mantida sob refluxo durante uma noite. O produto da reação foi purificado por recristalização em metanol aquecido à temperatura de ebulição (aproximadamente $64^{\circ} \mathrm{C}$ ). Obteu-se dessa maneira um sólido cristalino verde esmeralda que foi mantido sob vácuo até não se observar mais perda de massa.

A análise elementar de carbono e hidrogênio foi consistente com os valores calculados, como pode ser observado na tabela a seguir.

\begin{tabular}{|c|c|c|}
\hline & Experimental & Calculado \\
\hline$\% \mathrm{C}$ & 19,97 & 20,1 \\
\hline$\% \mathrm{H}$ & 3,2 & 3,37 \\
\hline
\end{tabular}


Tabela 2.1: Análise elementar de carbono e hidrogênio do $\mathrm{Rh}_{2}\left(\mathrm{C}_{2} \mathrm{H}_{3} \mathrm{O}_{2}\right) 4.2 \mathrm{H}_{2} \mathrm{O}$.

\subsection{Síntese das Porfirinas Supermoleculares}

As porfirinas supermoleculares foram obtidas pela coordenação de quatro complexos binucleares de acetato de ródio aos átomos de nitrogênio piridínidos periféricos de meso-tetrapiridilporfirinas (TPyPs). A estabilidade dessas supermoléculas e consequentemente o estabelecimento de um método adequado de preparação é dificultado pela labilidade dos ligantes axiais do complexo de ródio. Além disso, a grande diferença nas constantes de formação da primeira e segunda ligação axial, praticamente exclui a possibilidade de formação de espécies oligoméricas, a não ser em condições de elevada concentração e excesso de porfirina. A baixa solubilidade da porfirina e a labilidade também é um problema no momento de se fazer o estudo desses compostos pois um excesso do composto periférico deve ser adicionado para manter a integridade do complexo e evitar a precipitação da porfirina.

Vários testes em pequena escala foram realizados para se definir as melhores condições experimentais de síntese, variando-se o solvente, a temperatura e o tempo de reação. Os resultados foram analisados por métodos espectroscópicos e eletroquímicos. Testou-se alguns solventes como $\mathrm{CHCl}_{3}$, trifluoretanol, DMSO, metanol, etanol e também algumas misturas destes. Nenhum destes solventes porém se mostrou adequado para a realização da síntese, devido a problemas 
relacionados às solubilidades dos compostos. Testes de variação da temperatura e tempos de reação nos solventes anteriormente citados também foram efetuados na tentativa de se obter a melhor condição experimental.

Outro fato a ser também levado em consideração é referente à labilidade ${ }^{[43]}$ das posições axiais do composto binuclear de ródio. Devido a esse aspecto, várias tentativas de síntese e purificação foram feitas, pois caso o solvente usado seja coordenante, a porfirina da supermolécula já formada pode ser trocada por uma molécula deste solvente, destruindo a estrutura supramolecular.

Após diversos testes prévios em escala reduzida para otimizar o processo e também obter melhores rendimentos e resultados, verificou-se que usar meio reacional de ácido acético em quantidade necessária apenas para a solubilização completa dos reagentes, à temperatura ambiente, seria mais adequado para a obtenção da nova porfirina supermolecular, uma vez que neste meio, todos os precursores se encontram solúveis.

Assim duas novas porfirinas supermoleculares (Figura 2.1) foram obtidas através da coordenação de quatro complexos dinucleares de ródio aos quatro grupos piridina da 3TPyP (Figura 1.1C) e da 4TPyP (Figura 1.1B), em ácido acético glacial. A 4TPyP utilizada como reagente de partida foi de origem comercial (Aldrich). 

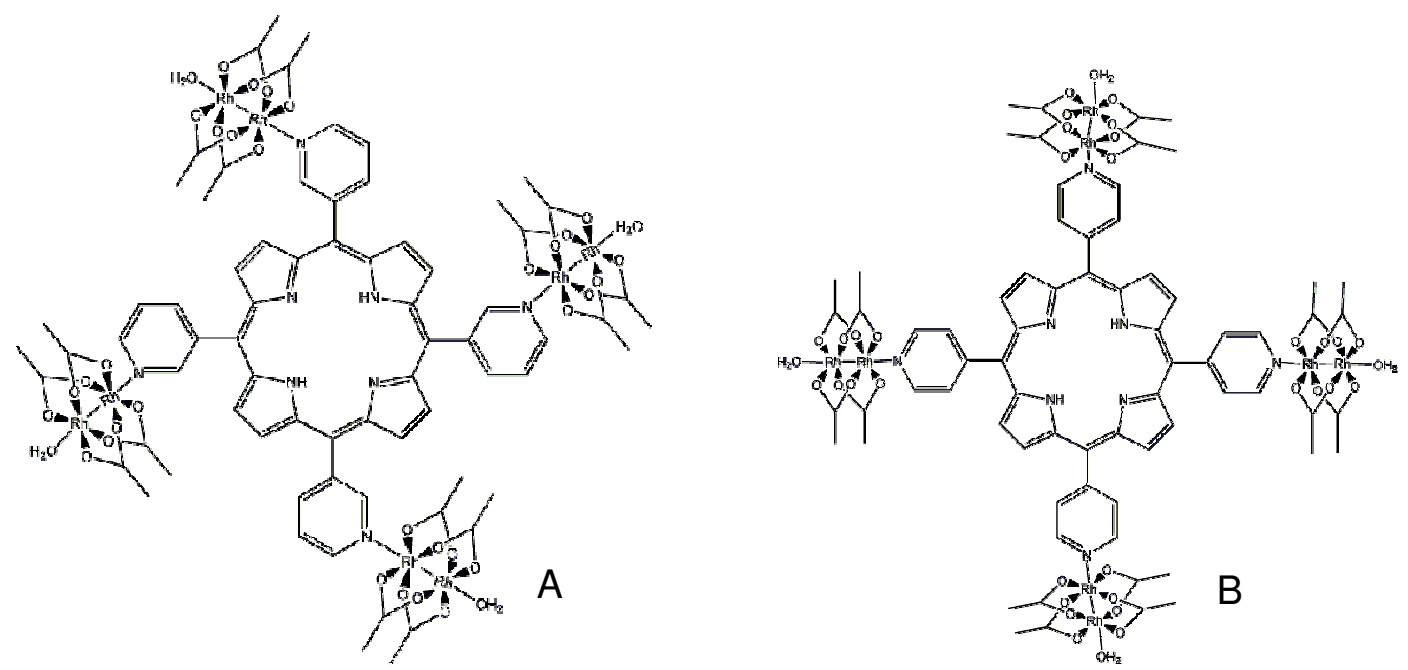

Figura 2.1: Estruturas das supermoléculas: $A:\left[R h_{2}(O A c)_{4}\left(H_{2} O\right)\right]_{4} T 3 P y P$ e $B:\left[R h_{2}(O A c)_{4}\left(H_{2} O\right)\right]_{4} T 4 P y P$.

Para obter a supermolécula a partir do isômero 3TPyP, foram usados 163,2 $\mathrm{mg}(0,3414 \mathrm{mmol})$ do composto dinuclear de ródio solubilizados em cerca de $30 \mathrm{~mL}$ de ácido acético glacial. Considerando-se que para a obtenção do composto tetracoordenado deveria ser usado quantidades estequiométricas de material de partida (4:1), a quantidade de porfirina a ser utilizada seria de 51,22 mg. Porém, optou-se por usar um pequeno excesso do composto de ródio para assegurar a formação das espécies tetra-substituídas. Usou-se então apenas 48mg de porfirina base livre.

A reação ficou sob agitação magnética por cerca de 40 horas e teve seu solvente retirado por rotoevaporação. O composto obtido nessa síntese apresenta coloração púrpura (violeta escuro), característico da porfirina, e foi lavado várias 
vezes com clorofórmio, que é um solvente não coordenante, para que quaisquer resquícios de ácido acético fossem removidos.

Para a obtenção da supermolécula a partir do isômero 4TPyP, usou-se 158,3 mg do composto dinuclear de ródio em cerca de $50 \mathrm{~mL}$ de ácido acético glacial e 50 mg de porfirina também em ácido acético. O procedimento sintético seguido foi análogo ao do isômero descrito anteriormente, pois uma vez que já se conheciam os pontos problemáticos (como a questão da labilidade e solubilidade dos compostos), a obtenção desta supermolécula teve seus erros minimizados. Apesar desse derivado se apresentar solúvel numa menor quantidade de solventes que o anterior, não houve diferença significativa entre as sínteses das espécies. A tabela a seguir apresenta resultados experimentais e calculados de análise elementar de carbono, nitrogênio e hidrogênio para o isômero 3TPyP.

\begin{tabular}{|c|c|c|}
\hline & Calculado & Experimental \\
\hline$\% \mathrm{C}$ & 35,17 & 34,41 \\
\hline$\% \mathrm{H}$ & 3,36 & 3,4 \\
\hline$\% \mathrm{~N}$ & 4,56 & 4,28 \\
\hline
\end{tabular}

Tabela 2.2: Análise elementar de carbono, nitrogênio e hidrogênio para o isômero 3TPyP.

Para a caracterização completa das porfirinas supermoleculares, foram feitos vários experimentos que ajudaram a verificar o sucesso das reações e que possibilitassem um estudo mais aprofundado das propriedades dessas supermoléculas. Porém, uma boa caracterização dos precursores se faz necessária 
para o entendimento do processo geral. Assim, as técnicas utilizadas serão apresentadas, direcionando-se a discussão para a caracterização dos compostos considerados nessa dissertação. A seguir será discutido o método de preparação de nanopartículas de ouro reativas utilizadas para a montagem, camada por camada, de nanomateriais híbridos orgânico-inorgânicos e também os resultados de caracterização e aplicação como materiais ativos de sensores amperométricos.

\subsection{Síntese das Nanopartículas de ouro}

Nanopartículas de ouro podem ser obtidas por diferentes métodos de síntese, dos quais se destacam o método de redução por citrato e o método de Brust Schiffrin.

Para preparar nanopartículas de ouro, o método de redução por citrato tem sido o mais popularmente utilizado desde que foi introduzido por Turkrvitch ${ }^{[44]}$ em 1951. Este método consiste em usar citrato para promover a redução de íons $\mathrm{AuCl}_{4}{ }^{-}$ em água. As nanopartículas formadas dessa maneira estão estabilizadas através de repulsões eletrostáticas e pelos íons citrato, que além de participarem no processo de redução, atuam na passivação das AuNPs, evitando também a agregação das mesmas.

O método de Brust-Schiffrin ${ }^{[45]}$ publicado em 1994 permite a obtenção de AuNP estáveis, com dimensões reduzidas e uma estreita distribuição de tamanhos. A técnica de síntese consiste na redução de $\mathrm{AuCl}_{4}{ }^{-}$em tolueno por uma solução 
aquosa de $\mathrm{NaBH}_{4}$ num sistema de duas fases na presença de um agente surfactante, como o brometo de tetraoctilamônio (TOAB), que será o responsável por transferir os íons $\mathrm{AuCl}_{4}^{-}$para a fase orgânica, e de alcanotióis de cadeia longa, que irão atuar como agentes passivantes.

As nanopartículas de ouro utilizadas neste trabalho foram obtidas através do método de Brust-Schiffrin modificado ${ }^{[46]}$, interrompendo a reação antes que esta atingisse seu fim. As nanopartículas sintetizadas dessa maneira possuem maior reatividade em relação à incorporação de substratos em sua superfície, visto que apresentam sítios livres que podem ser usados para sua funcionalização. Essa modificação ainda permite que as nanopartículas geradas deste modo sejam mais estáveis, podendo ser armazenadas na forma de pó e ressuspendidas em solventes orgânicos no momento de seu uso.

\subsection{Modificação dos eletrodos: produção dos filmes nanoestruturados}

Sistemas supramoleculares constituídos por porfirinas e nanopartículas de ouro podem ser utilizados como materiais ativos de diversos tipos de sensores para as mais variadas substâncias químicas. Nesse sentido constitui-se uma estratégia bastante interessante e aplicável a imobilização dos compostos em eletrodos por meio de deposição organizada e controlada de material. Tal tratamento possibilita a transferência das propriedades catalíticas do material em questão para a superfície deste eletrodo, tornando mais fácil e prático a utilização destes em procedimentos 
analíticos. Neste trabalho foram usados eletrodos transparentes de vidro recobertos com óxido de estanho dopados com flúor (FTO) para a obtenção dos filmes.

Antes do preparo dos filmes híbridos sobre o eletrodo de FTO é necessário que este passe por um procedimento prévio que permitirá que sua superfície seja funcionalizada. Essa modificação do FTO possibilita que nanopartículas de ouro ou outros tipos de materiais sejam ancorados em sua superfície, dando início à primeira camada do filme.

Na tentativa de se obter uma melhor funcionalização do FTO, dois tipos de procedimentos foram testados. Um consiste em usar (3-mercaptopropil)trimetoxisilano (3-MPTS) como modificador ${ }^{[47]}$, sendo que este encontra-se ligado covalentemente à superfície do FTO.

Para este procedimento, placas de cerca de $3 \mathrm{~cm}^{2}$ de eletrodos de FTO foram previamente limpas com solução piranha a $85^{\circ} \mathrm{C}$ durante 15 minutos. Em seguida permaneceram imersas em uma solução $5 \%$ de 3-MPTS (v/v), em tolueno, a $37^{\circ} \mathrm{C}$. Depois de quatro horas imersas nessa solução as placas foram lavadas com uma mistura de etanol/tolueno (1:1) e submetidas a tratamento térmico a $105^{\circ} \mathrm{C}$ durante 16 horas. As placas foram estocadas em metanol até o momento do uso.

A figura a seguir esquematiza as etapas de silanização do eletrodo de vidro. 


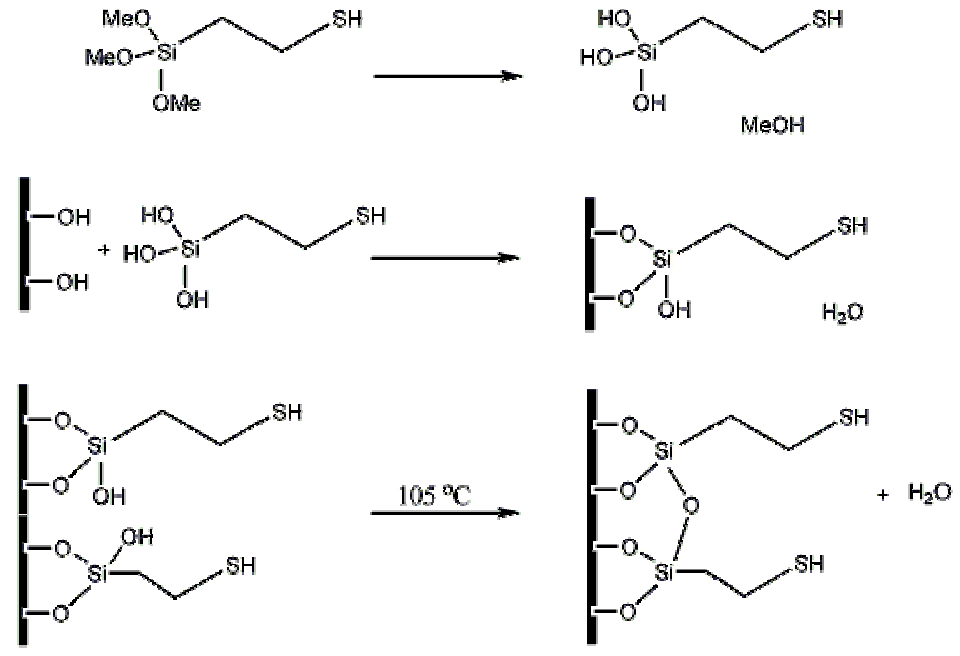

Figura 2.2: Esquema mostrando o processo de silanização usando (3-mercaptopropil)trimetoxisilano.

O outro procedimento de modificação da superfície se baseia em usar ácido isonicotínico para tal propósito. O método consiste em imergir os eletrodos de FTO durante 12 horas em uma solução de ácido isonicotínico de concentração $5.10^{-5} \mathrm{M}$ em metanol. Após esse período os eletrodos foram retirados da solução e lavados com o mesmo solvente antes que secassem, para que o excesso de ligante fosse retirado. Este procedimento de lavagem faz com que restem na superfície apenas aquelas moléculas que efetivamente estão ligados ao vidro condutor.

As figuras a seguir se referem a imagens de microscopia de varredura (MEV) de eletrodos modificados com ácido isonicotínico (A) e 3-MPTS (B), ambos tendo uma bicamada de AuNP e porfirina. 

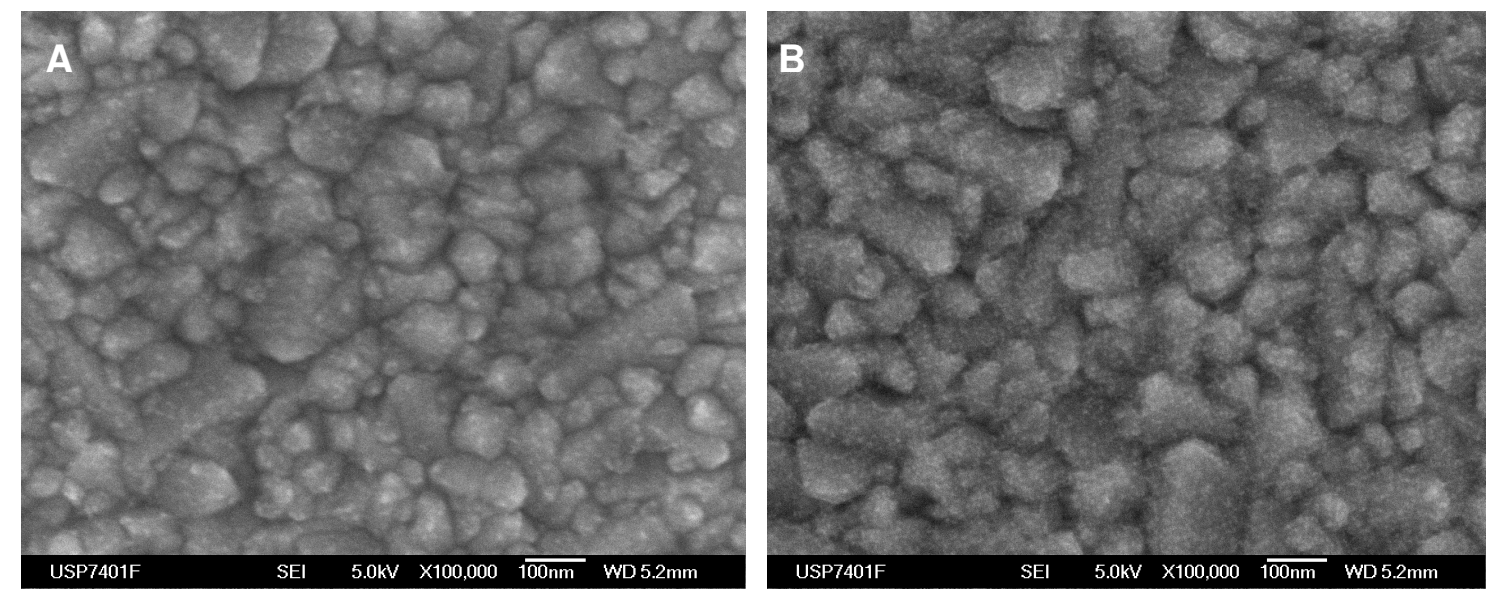

Figura 2.3: Imagens de microscopia de varredura de eletrodos de FTO modificados com ácido isonicotínico (A) e 3-MPTS (B).

Observando-se as imagens, pode-se perceber que não existem diferenças significativas entre os dois tipos de recobrimento, sendo que ambos se mostraram bem eficientes para a modificação desejada. Por se tratar de um procedimento mais simples, mais barato e mais rápido, optou-se por adotar o ácido isonicotínico como modificador do FTO.

Após a modificação da superfície do vidro vários tipos de filmes supramoleculares híbridos eletrostaticamente montados foram obtidos através do método de dip-coating.

Conforme dito anteriormente, os filmes foram montados camada por camada. Cada camada do filme foi obtida mergulhando-se a placa de vidro já previamente modificada pelo ácido isonicotínico em diferentes soluções de AuNP e do respectivo ligante que se deseja utilizar como espaçador/modificador. 
A seguir será descrito detalhadamente o procedimento de preparo seguido apenas para um dos filmes, o de 3TPyP e AuNP. O processo de obtenção de todos os outros (exceto aquele que possui apenas três camadas de AuNP e uma de acetato de ródio) segue sempre o mesmo procedimento padrão, substituindo-se apenas as soluções A e B do esquema da Figura 2.4 por soluções das respectivas estruturas que irão compor o nanomaterial, portanto os demais não serão abordados minuciosamente.

\section{A. 3TPyP/AuNP}

Para este filme de 3TPyP e AuNP, a placa foi imersa inicialmente em uma solução recém preparada $(A)$ de nanopartículas de ouro $\left(a b s_{520 n m}=0,8\right)$ em tolueno. Após cinco minutos de imersão, a placa foi retirada da solução e lavada com o mesmo solvente. Após essa lavagem, o eletrodo foi então mergulhado por também cinco minutos em uma solução (B) de 3TPyP em tolueno/ $\mathrm{CHCl}_{3}$ 1:1 (absorbância $\left.a_{52 n m}=0,8\right)$. O mesmo procedimento de lavagem no respectivo solvente é imediatamente feito quando a placa é retirada da solução, encerrando a primeira bicamada. Estes procedimentos de lavagem após a imersão em cada solução são necessários pelo mesmo motivo daquela feita depois da modificação com ácido isonicotínico: para que apenas permaneçam as partículas e/ou moléculas efetivamente ligadas à camada anterior. Este processo de produção foi repetido até que se completassem dez bicamadas. 
Após essas etapas, os eletrodos são então deixados sob vácuo até o momento do uso e já se encontram prontos para serem utilizados nos experimentos. O esquema do procedimento descrito é ilustrado pela Figura 2.4 a seguir.

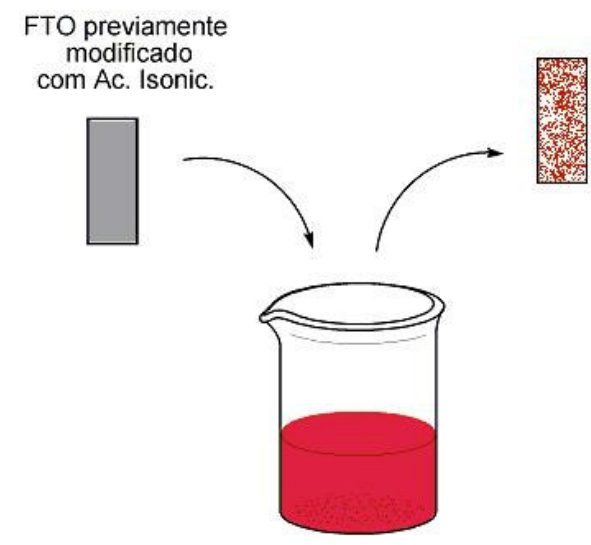

A

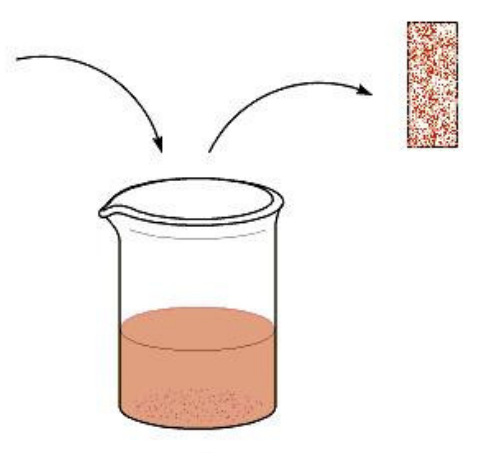

B

Figura 2.4: Esquema do procedimento experimental de obtenção do filme de AuNP (solução A) e 3TPyP (solução B).

\section{B. M-3TPyP/AuNP e 4TPyP/AuNP}

Os filmes de materiais híbridos orgânico-inorgânicos M-TPyP/AuNP, onde $\mathrm{M}=\mathrm{Fe}$ (III) e $\mathrm{Co}(\mathrm{III})$, o procedimento também segue conforme o esquema anterior, em que a solução "A" é de AuNP em tolueno e a solução "B" neste caso é de M-TPyP em uma mistura 1:1 de metanol e tolueno. Para o filme de 4TPyP/AuNP, a diferença está apenas na segunda solução (B), em que foi usada a porfirina 4TPyP, solubilizada em uma mistura 1:1 de clorofórmio e tolueno, em lugar da M-TPyP. 


\section{3TPyP-Rh/4,4'-Bipy}

Este filme adota o mesmo procedimento técnico de obtenção, porém não usou-se AuNP como conector entre as camadas de porfirina e sim o ligante 4,4'bipy. A solução "A" é da supermolécula 3TPyP-Rh em clorofórmio e a solução "B" neste caso é de 4,4'-bipy em metanol.

\section{3TPyP-Rh / AuNP / 4-Mpy}

Para os filmes constituídos por uma maior quantidade de elementos estruturais, como por exemplo o filme derivado de AuNP e supermolécula, tendo 4MPy como ligante ponte entre as espécies, a diferença no procedimento está, basicamente, na inserção de uma ou mais soluções de imersão. Portanto, para a produção deste filme, adotou-se um procedimento que apresenta uma etapa a mais, referente à imersão na solução do conector, ou seja, o eletrodo modificado por ácido isonicotínico será imerso em soluções de AuNP, 4-MPy, supermolécula, 4-MPy e AuNP durante cinco minutos cada, respectivamente. A Figura 2.5 a seguir é uma representação ilustrativa de uma bicamada. O procedimento também foi repetido até que dez bicamadas do filme fossem completadas. 


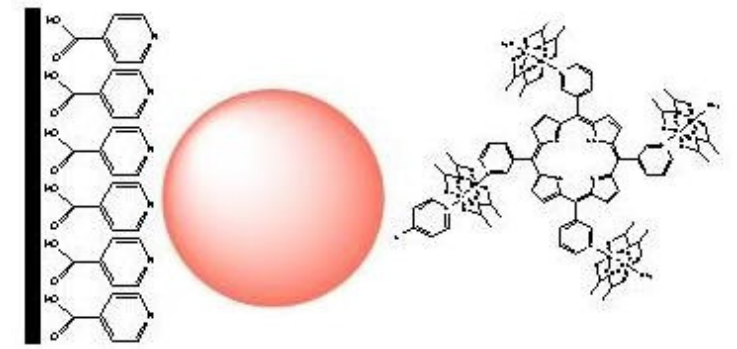

Figura 2.5: Representação ilustrativa de uma bicamada do filme a ser obtido.

O crescimento dos filmes nanoestruturados foi acompanhado por espectroscopia UV-vis. Pode-se observar que a intensidade da banda de plasmon superficial da AuNP (520 nm) é linearmente dependente do número de bicamadas do material, como pode ser verificado na Figura 2.6 a seguir. Nota-se também que a banda Soret da porfirina aparece como um ombro em torno de $450 \mathrm{~nm}$, evidenciando a presença desse macrociclo no nanomaterial.

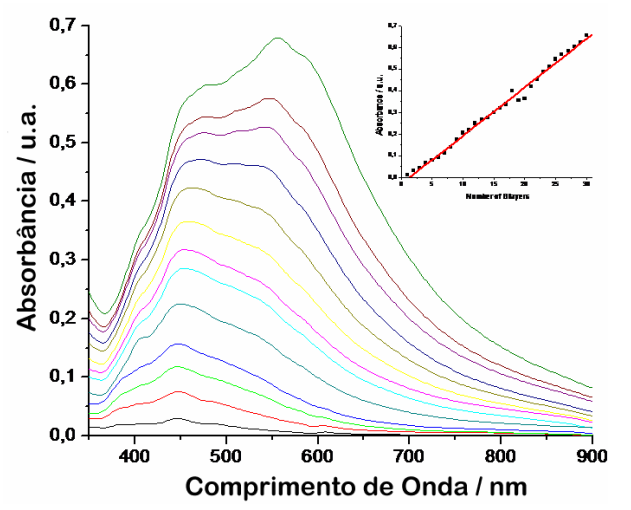

Figura 2.6: Acompanhamento do crescimento do filme de 3TPyP/AuNP por espectroscopia UV-vis. 


\section{E. AuNP/3TPyP/Rh}

Apesar de adotar o mesmo procedimento técnico de obtenção, este além de apresentar menor número de camadas que os anteriores, também possui uma estrutura um pouco diferente das demais. Este filme apresenta somente três camadas de AuNP e três de 3TPyP, intercaladas, sendo que por último, foi feita a deposição de apenas uma monocamada do complexo de ródio. Logo, o interior do

filme é composto de apenas AuNP e 3TPyP, recoberto externamente por uma camada do complexo binuclear de ródio. 


\section{Espectroscopia Eletrônica}

A espectroscopia eletrônica é uma poderosa ferramenta na identificação de compostos porfirínicos, visto que os mesmos apresentam bandas características na região do ultravioleta e do visível.

As metaloporfirinas se caracterizam pela presença de uma banda intensa em torno de $420 \mathrm{~nm}$, denominada banda Soret e duas bandas mais fracas, em torno de 500 e $600 \mathrm{~nm}$, denominadas bandas $\mathrm{Q}_{0-0}$ e $\mathrm{Q}_{0-1}$. Contudo, essas duas bandas se desdobram em quatro no caso das porfirinas bases livres por causa da diminuição da simetria da molécula de $D_{4 h}$ para $D_{2 d}{ }^{[48]}$.
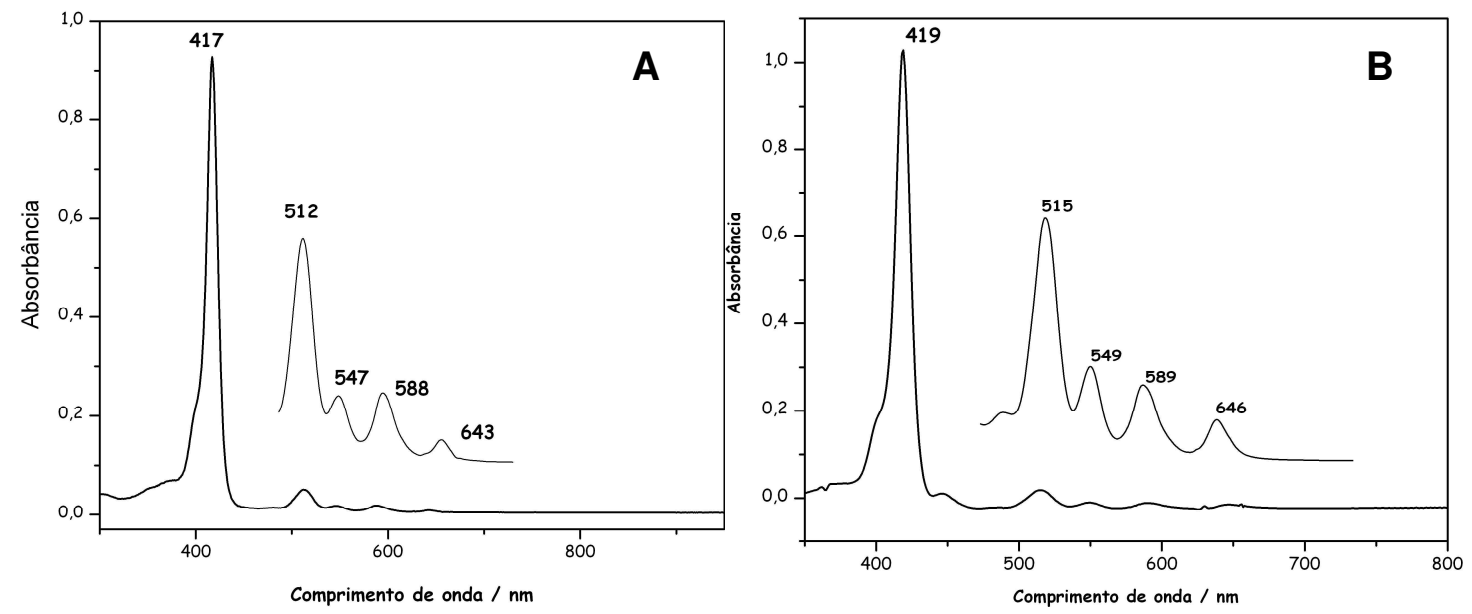

Figura 3.1: Espectro eletrônico da A: 4TPyP base livre, concentração $2.10^{-5} \mathrm{M}$ em $\mathrm{CHCl}_{3}$ e B: 3TPyP base livre.

O espectro eletrônico do acetato de ródio em água consiste em duas bandas no visível, uma em $587 \mathrm{~nm}$, chamada banda 1 e outra em $445 \mathrm{~nm}$, chamada de 
banda 2 e mais duas no UV, a banda 3, em 250 nm (ombro) e banda 4, em 219 nm, como pode ser visualizado na Figura 3.2 a seguir.

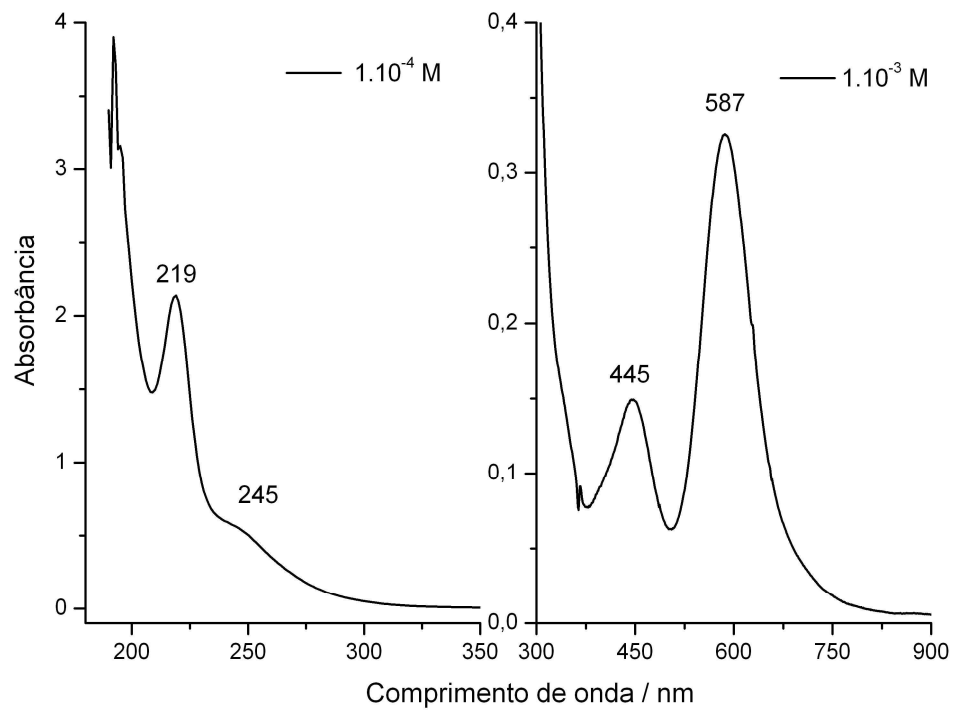

Figura 3.2: Espectro eletrônico do complexo binuclear de ródio em água, concentração $1.10^{-4} \mathrm{M}$ (visualização das bandas 3 e 4) e $1.10^{-3} \mathrm{M}$ (visualização das bandas 1 e 2).

O espectro eletrônico da 3TPyP-Rh que pode ser visualizado na Figura 3.3 a seguir, foi obtido em solução de clorofórmio e apresenta um perfil característico da porfirina base-livre com pequenos deslocamentos no máximo das bandas, quando comparado com a 3TPyP. Observa-se também que não ocorre aumento no número de bandas apesar da menor simetria da molécula de 3TPyP, demonstrando que as características espectrais são definidas apenas pela simetria do anel porfirínico.

O espectro das porfirinas supermoleculares são muito similares aos das porfirinas de partida, sendo observados apenas pequenas alterações nas posições das bandas. Isto decorre do fato do complexo binuclear de ródio apresentar 
transições de intensidade muito menores que os da porfirina e não haver uma interação suficientemente forte para perturbar significativamente os níveis eletrônicos da mesma. Além disso, o não aparecimento de transições de transferência de carga [Rh-Rh] para porfirina pode ser um indicativo de um baixo acoplamento eletrônico entre os complexos periféricos e o anel central. Logo, o espectro é basicamente a sobreposição dos espectros dos grupos periféricos e central.

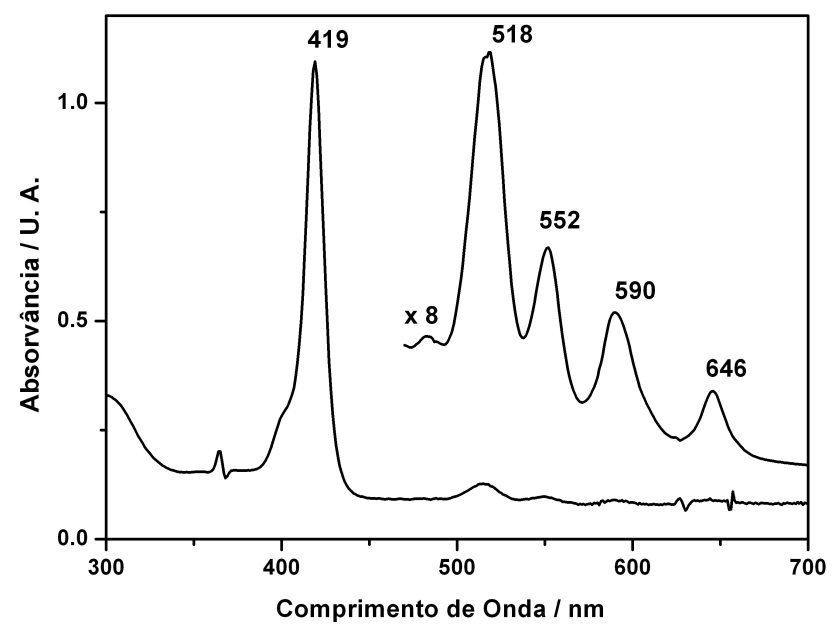

Figura 3.3: Espectro eletrônico da $\left[R h_{2}(\mathrm{OAc})_{4}\left(\mathrm{H}_{2} \mathrm{O}\right)\right]_{4} \mathrm{~T} 3 \mathrm{PyP}$ em $\mathrm{CH}_{2} \mathrm{Cl}_{2}$. 


\section{Termogravimetria - TG}

Todos os dados de termogravimetria foram obtidos num instrumento Shimadzu modelo TGA50 e/ou DTA-50, usando uma velocidade de aquecimento de $10 \stackrel{\circ}{\circ}$ por minuto, sob fluxo constante $(50 \mathrm{~mL} / \mathrm{min})$ de gás nitrogênio ou ar sintético. As curvas foram obtidas na faixa de temperatura de 20 a $900^{\circ} \mathrm{C}$, utilizando-se um cadinho de platina contendo aproximadamente $4 \mathrm{mg}$ de amostra.

Na Figura 4.1 a seguir, analisando-se as curvas TG e DTG da 3TPyP, podese concluir que estas apresentam um único processo que pode ser atribuído à decomposição térmica da porfirina, que tem início em aproximadamente $490 \stackrel{\circ}{\circ}$. A curva termogravimétrica do complexo $\left[\mathrm{Rh}_{2}(\mathrm{OAc})_{4}\left(2 \mathrm{H}_{2} \mathrm{O}\right)\right]$ apresenta dois processos, sendo que o primeiro corresponde à saída das águas de hidratação em $125{ }^{\circ} \mathrm{C}$ $(7,46 \%)$. O segundo processo corresponde à posterior perda dos ligantes acetato a $300 \stackrel{\circ}{ }{ }^{C}(47,73 \%)$. Cálculos estequiométricos correlacionando-se o percentual de

perda de massa e a massa molar dos complexos indicam que se obtém $\mathrm{Rh}^{0}{ }^{[49]}$ no final do processo, depois da perda dos acetatos e destruição da estrutura em forma de gaiola. Contudo, com o aumento posterior de temperatura verificou-se um aumento de massa, $(8,58 \%)$ provavelmente devido à formação de óxidos.

A supermolécula estudada apresenta um comportamento térmico semelhante ao do cluster de Rh, e um processo de decomposição térmica iniciando em torno de 275 ㅇ. Pela curva DTG, pode-se observar a presença de dois processos 
sucessivos, que podem ser atribuídos à decomposição térmica do cluster de Rh e da porfirina em temperaturas menores, ou seja, a termodecomposição da porfirina catalisada pela presença do complexo de ródio. Porém, pode-se observar uma lenta perda de massa, cujo início se aproxima do começo da decomposição térmica da porfirina.
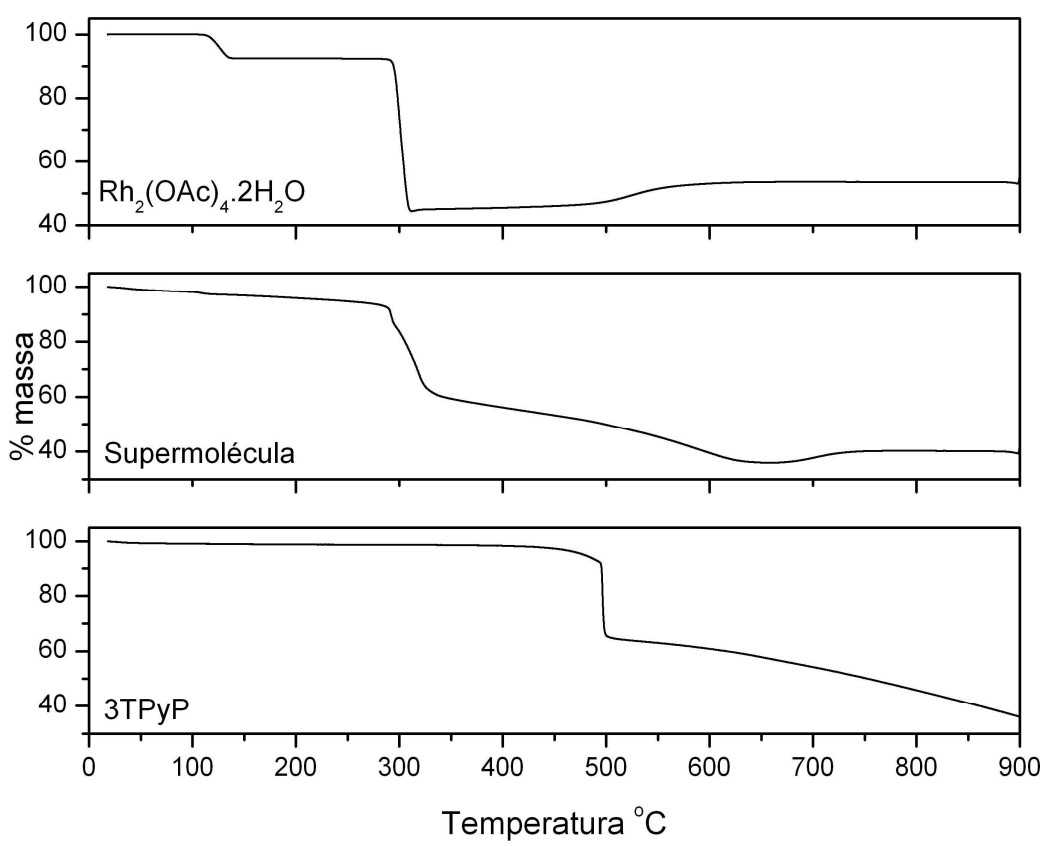

Figura 4.1: Comportamento térmico da 3TPyP-Rh e de seus precursores em atmosfera de nitrogênio.

O termograma da Figura 4.1 mostrou o comportamento termogravimétrico do novo composto supramolecular e sugere que a decomposição do anel porfirínico na 
supermolécula ocorre em temperaturas menores, mostrando que o Rh pode auxiliar no processo de decomposição desta, atuando como um catalisador.

Apesar da grande labilidade da ligação entre o cluster de ródio e a água, e da utilização de ácido acético na mistura reacional, pelos estudos termogravimétricos efetuados, pode-se concluir que a supermolécula continua apresentando moléculas de água como ligantes axiais. Para 0 isômero derivado da 4TPyP $\left(\mathrm{Rh}_{2}(\mathrm{OAc})_{4}\left(\mathrm{H}_{2} \mathrm{O}\right)\right]_{4} \mathrm{~T}$ 4PyP $)$ um comportamento análogo pode ser observado. $\mathrm{O}$ processo de decomposição da supermolécula tem início em aproximadamente $280^{\circ} \mathrm{C}$. Esta temperatura é menor que a temperatura de decomposição da porfirina base livre, que tem esse processo iniciado em torno de $550^{\circ} \mathrm{C}$, como pode se observado na Figura 4.2 a seguir.

Assim como para a supermolécula derivada da 3TPyP, para o isômero derivado da 4TPyP, os complexos de ródio atuam como um catalisador, diminuindo a temperatura em que o processo de decomposição térmica se inicia em comparação à decomposição da porfirina base livre, que tem início em torno de $550^{\circ} \mathrm{C}$ 

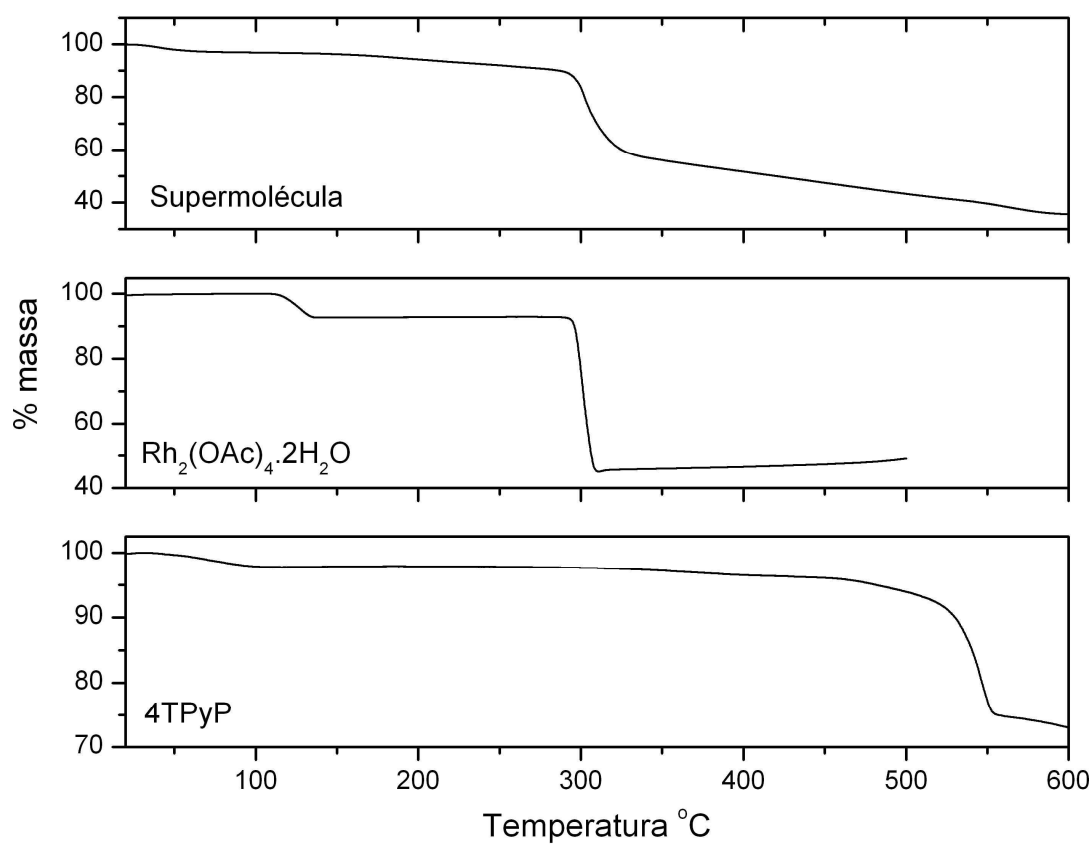

Figura 4.2: Comportamento térmico da 4TPyP-Rh e de seus precursores. 


\section{Ressonância Magnética Nuclear - RMN}

Os espectros de ressonância magnética nuclear de prótons unidimensional ( $\left.{ }^{1} \mathrm{H}-\mathrm{RMN}\right)$ foram obtidos em um espectrofotômetro Varian $300 \mathrm{MHz}$, modelo INOVA 1, da central analítica do IQ-USP.

Para a $\left[R h_{2}(\mathrm{OAc})_{4}\left(\mathrm{H}_{2} \mathrm{O}\right)\right]_{4} \mathrm{~T} 3 \mathrm{PyP}$ o simpleto característico dos prótons ligados aos átomos de nitrogênio internos e blindados pela corrente no anel porfirínico aparece em -2,70 ppm, em região de campo alto, com intensidade correspondente a $2 \mathrm{H}$.

O sinal dos prótons nas posições beta-pirrólicos aparece como um simpleto em 9,25 ppm e intensidade correspondente a $8 \mathrm{H}$. Aparece em campo baixo devido à desblindagem originada pela corrente do anel, que também é responsável pela blindagem dos prótons internos do anel. Nas piridinas, o sinal do hidrogênio na posição $\mathbf{f}$ corresponde a um simpleto em 9,98 ppm de intensidade correspondente a 4H. Os outros três sinais estão em h: 9,65 (dupleto), i: 8,90 (tripleto) e j: 8,17 ppm (dupleto), todos eles com intensidade correspondente a $4 \mathrm{H}$. 


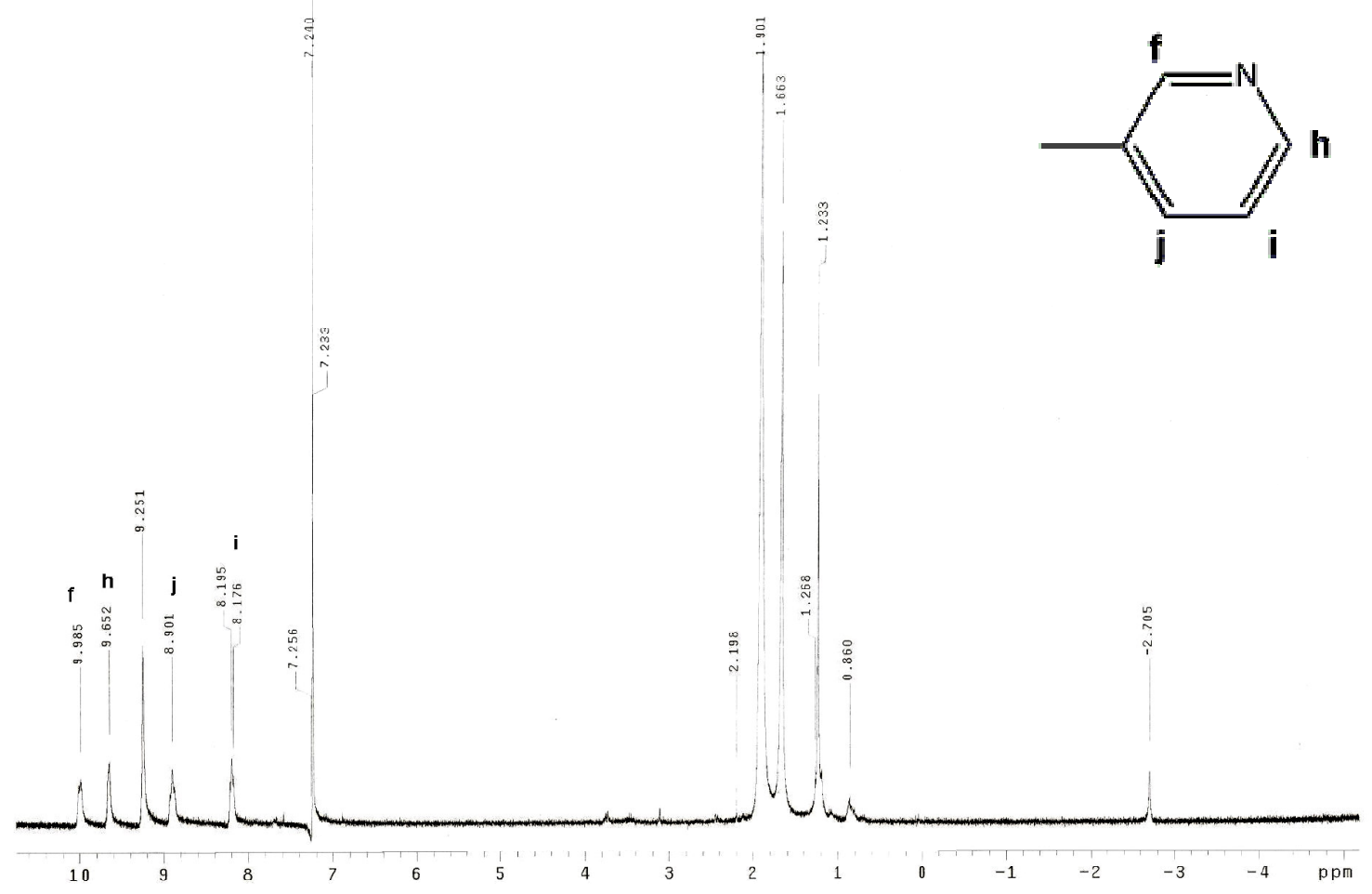

Figura 5.1: Espectro de $\mathrm{RMN}$ da $\left[\mathrm{Rh}{ }_{2}(\mathrm{OAc})_{4}\left(\mathrm{H}_{2} \mathrm{O}\right)\right]_{4} \mathrm{~T} 3 \mathrm{PyP}$ em $\mathrm{CDCl}_{3}$.

O sinal (sinmpleto) das metilas dos ligantes acetato dos complexos dinucleares de ródio aparecem em 1,90 ppm. Esses valores são diferentes dos encontrados nas unidades livres, confirmando a coordenação.

A porfirina supermolecular $\left[\left\{\mathrm{Rh}_{2}(\mathrm{OAc})_{4}\left(\mathrm{H}_{2} \mathrm{O}\right)\right\}_{4} \mathrm{~T}\right.$ 4PyP $]$ é um isômero mais simétrico da $\left[\left\{\mathrm{Rh}_{2}(\mathrm{OAc})_{4}\left(\mathrm{H}_{2} \mathrm{O}\right)\right\}_{4} \mathrm{~T} 3 \mathrm{PyP}\right]$. De fato, essa molécula tem eixo de simetria $\mathrm{C}_{4}$ fazendo com que aumente o número de prótons equivalentes, ou seja, diminua o número de sinais. Neste caso, o sinal dos prótons pirrólicos aparece em 9,28 ppm, com intensidade de $8 \mathrm{H}$. Os sinais das piridinas podem ser encontradas como dois dupletos em 9,64 (a) e 8,65 ppm (b) de igual intensidade (8H). O sinal das metilas 
do complexo de ródio aparece em 2,07 ppm com intensidade correspondente a 48H. Note que o sinal se encontra deslocado para campos mais baixos em relação ao isômero meta, indicando que os grupos metila dos acetatos se encontram localizados numa região de maior influência da corrente de anel da porfirina. Por outro lado, a mudança da posição do átomo de nitrogênio pidirínico de meta para para também aumenta o acoplamento eletrônico dos complexos periféricos com o anel porfirínico, de tal modo que os efeitos eletrônicos da interação entre eles não podem ser descartados.

A diferença observada no deslocamento químico do sinal dos prótons internos das porfirinas supermoleculares (meta e para) pode ser decorrente tanto de efeitos eletrônicos como pode ser decorrente do efeito da corrente de anel, tendo em vista a diferença entre as disposições espaciais das mesmas nos dois casos. Por outro lado, no caso do derivado para- (Figura 5.2, o sinal está sendo indicado por "c") existe um acoplamento eletrônico significativo entre os complexos periféricos dinucleares e o anel, enquanto que no caso do isômero meta- há um plano nodal no átomo de carbono que liga o grupo piridil ao anel porfirínico. Deve-se também levar em consideração que a distância média das metilas ao anel porfirínico é grande no caso do isômero para- e menor no caso do meta, sendo difícil saber qual dos dois fatores é predominante. 


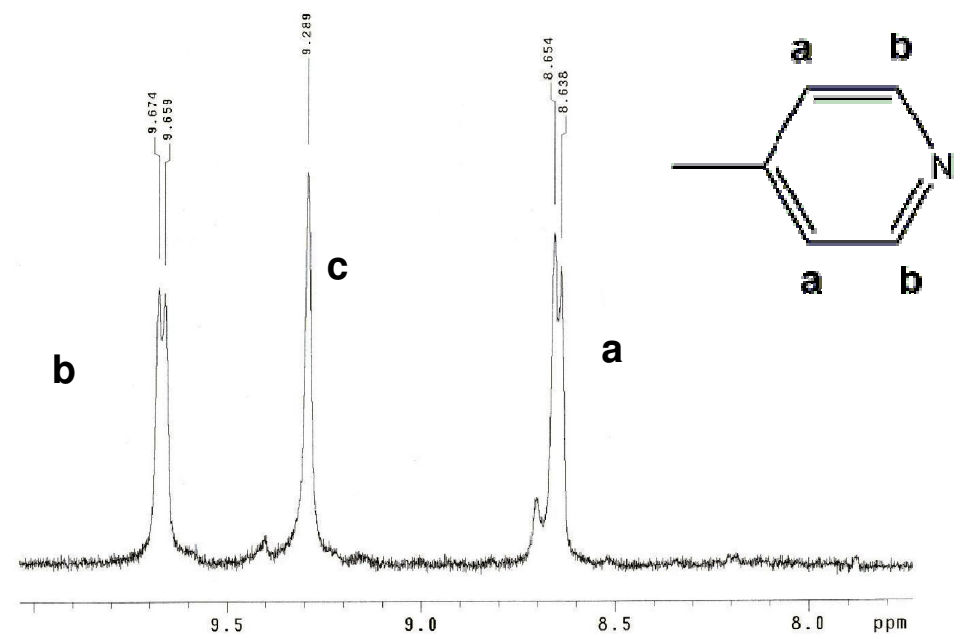

Figura 5.2: Espectro RMN de ${ }^{1} \mathrm{H}$ da $\left[\mathrm{Rh}_{2}(\mathrm{OAc})_{4}\left(\mathrm{H}_{2} \mathrm{O}\right)_{4} \mathrm{~T} 4 \mathrm{PyP}\right.$ em $\mathrm{CDCl}_{3}$. 


\section{Eletroquímica}

A voltametria cíclica consiste em um método rápido e fácil de estudar as reações de oxidação-redução em solução. Esta técnica também permite ter uma visão das reações químicas acopladas à transferência de elétrons ou ainda estudar as propriedades eletrocatalíticas dos compostos e materiais.

Os voltamogramas cíclicos foram obtidos utilizando-se um potenciostato/galvanostato da Autolab, modelo PGSTAT 30, acoplado a um microcomputador. A cela eletroquímica utilizada foi a convencional, de três eletrodos: eletrodo de trabalho (disco de platina), eletrodo de referência (fio de platina imerso em solução de $\mathrm{AgNO}_{3}$ 0,01 M/ TEAClO 4 0,1 M em acetonitrila) e eletrodo auxiliar (fio de platina helicoidal). Os experimentos foram realizados em 1,2dicloroetano seco, utilizando como eletrólito suporte $\mathrm{TBAPF}_{6}$ 0,05 M. Todos os potenciais foram referenciados em relação ao eletrodo padrão de hidrogênio (EPH) somando-se 0,503 V aos valores obtidos em relação ao eletrodo de referência experimental.

A porfirina base livre (3TPyP) é eletroquimicamente ativa e exibe quatro processos redox, duas reduções e duas oxidações na faixa de -1,5 a 1,8V (Figura 6.1), sendo que a segunda oxidação do anel dificilmente é observada, uma vez que a espécie gerada é muito reativa tornando-se necessário o uso de solventes extremamente secos, com baixíssimos teores de impurezas como a água. 
Analisando-se a região de potenciais negativos, observa-se a primeira redução monoeletrônica do anel porfirínico como um par de ondas reversíveis com $E_{1 / 2}=-0,86 \mathrm{~V}$, seguida da segunda redução monoeletrônica reversível do anel em $E_{1 / 2}=-1,19 \mathrm{~V}$. Analisando-se a região de potenciais positivos, pode-se verificar que os processos de oxidação do anel são irreversíveis e mal resolvidos, sendo observado uma onda anódica em $\mathrm{E}_{\mathrm{pa}}=1,53 \mathrm{~V}$, precedida por um ombro em torno de $1,4 \mathrm{~V}$.

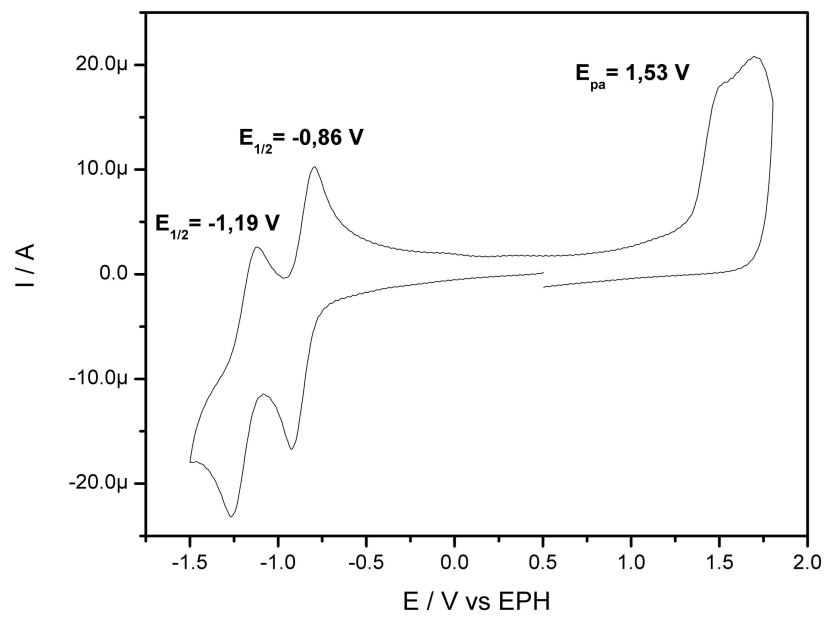

Figura 6.1: Voltamograma típico da porfirina base livre, 3TPyP em 1,2-dicloroetano, eletrólito suporte TBAPF $_{6}$ 0,05 M.

O voltamograma cíclico do composto dimérico de ródio (Figura 6.2 abaixo) apresenta um processo redox reversível, com $\mathrm{E}_{1 / 2}=1,12 \mathrm{~V}$ (complexo aquo). $\mathrm{A}$ separação entre os picos catódico e anódico está na faixa de 60 a 90mV. A razão entre as correntes de pico anódico ( $\left.\mathrm{i}_{\mathrm{pa}}\right)$ e pico catódico $\left(\mathrm{i}_{\mathrm{pc}}\right)$ fica próximo de um, indicando a ausência de reações químicas acopladas. 
O processo de oxidação dos íons ródio se torna mais favorável à medida que a interação com o grupo axial se torna mais forte. Assim, o potencial diminui conforme o aumento da capacidade doadora do ligante sendo uma indicação de que a energia do orbital HOMO aumenta em função do aumento da densidade eletrônica induzida pelo ligante $\sigma$-doador.

Considerando-se o complexo dinuclear como um ácido fraco, deverá haver então a formação de ligações axiais mais fortes com ligantes $\pi$-receptores, como a piridina e seus derivados. A interação $\sigma$ com a piridina é bastante aumentada devido à retro-doação. Assim, a ligação axial do complexo é compreendida como essencialmente devido a interação $\sigma$, que entretanto é realçada pela característica $\pi$ receptora do ligante.

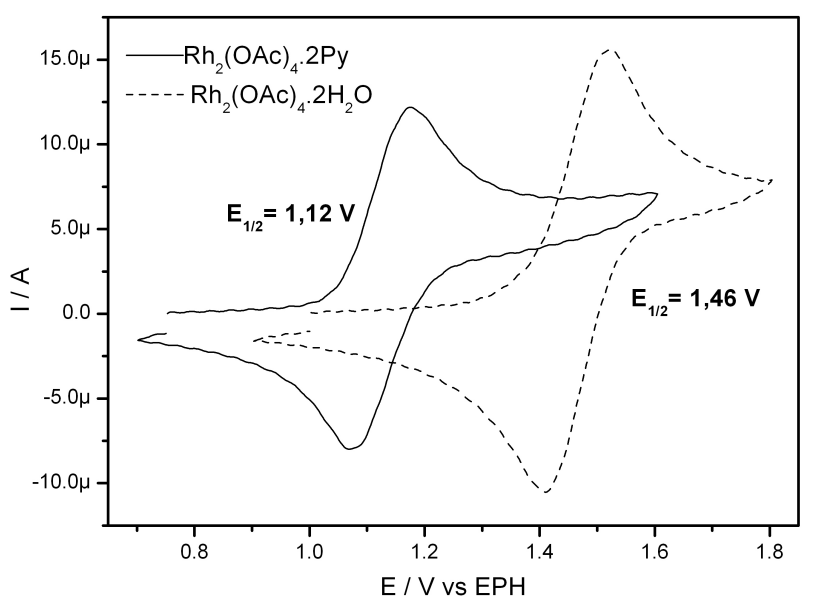

Figura 6.2: Voltamograma cíclico do complexo de ródio antes e depois da coordenação de piridina nas posições axiais em 1,2-dicloroetano seco, utilizando como eletrólito suporte TBAPF $_{6}$ 0,05 M. 
$\mathrm{Na}$ Figura 6.3 pode-se observar o comportamento eletroquímico da $\left[\left\{\mathrm{Rh}_{2}(\mathrm{OAc})_{4}\left(\mathrm{H}_{2} \mathrm{O}\right)\right\}_{4} \mathrm{~T} 3 \mathrm{PyP}\right]$. Partindo de $0,5 \mathrm{~V}$ e varrendo-se os potenciais na direção positiva e revertendo a varredura em $1,7 \mathrm{~V}$, observa-se o aparecimento de duas ondas reversível de intensidade similar. A primeira onda em 1,16 V ocorre num potencial análogo ao do complexo binuclear de ródio, podendo ser atribuido à espécie livre em solução gerada pela dissociação parcial do complexo. A segunda onda reversível é atribuída ao processo $\mathrm{Rh}_{2}{ }^{4+} / \mathrm{Rh}_{2}{ }^{5+}$ dos clusters coordenados à 3TPyP, pois seu potencial é 1,36 V, ou seja, $200 \mathrm{mV}$ deslocado para potenciais mais positivos. Este resultado é coerente com a coordenação de um ligante piridínico, como pode ser visto na Figura 6.3, que mostra a eletroquímica do composto de ródio tendo piridina como substituinte nas posições axiais. Contudo, a basicidade dos grupos piridilporfirina deve ser bem menor que da piridina, levando ao deslocamento da onda para potenciais mais positivos. Ainda na Figura 6.3, a segunda onda de oxidação, em 1,16 V corresponde ao cluster livre em solução. Observa-se também que a coordenação dos clusters promove uma variação nos potenciais redox do anel porfirínico. Segundo essa variação para potenciais mais altos, os clusters estão atuando como grupos retiradores de elétrons. 


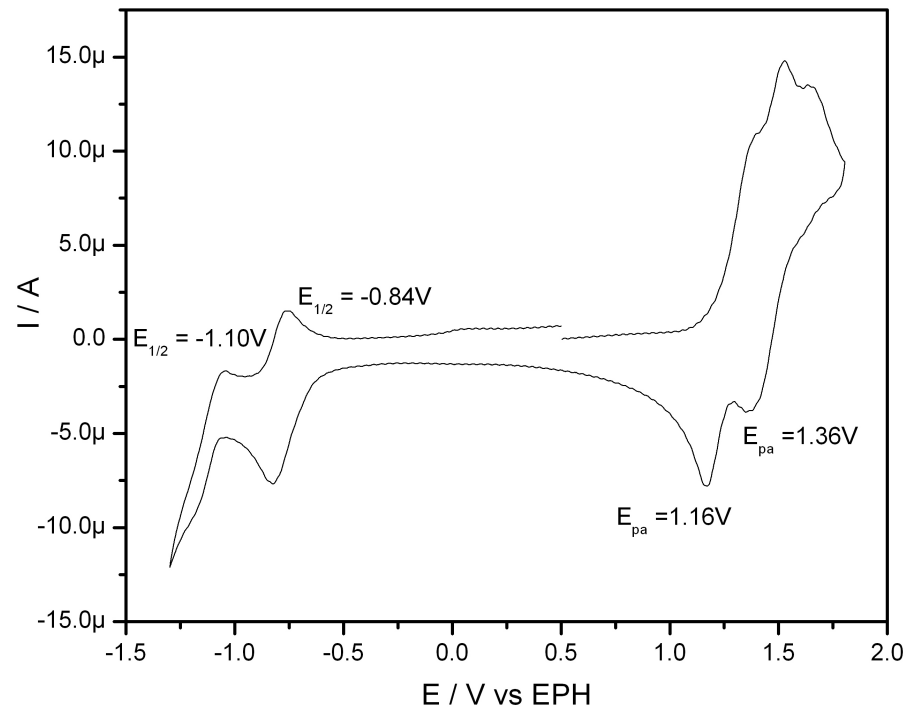

Figura 6.3: Voltamograma cíclico da $\left[\left\{\mathrm{Rh}_{2}(\mathrm{OAc})_{4}\left(\mathrm{H}_{2} \mathrm{O}\right)\right\}_{4} \mathrm{T3PyP}\right]$, em 1,2-dicloroetano, eletrólito suporte TBAPF $_{6}$ 0,05 M, e velocidade de varredura de $100 \mathrm{mV} / \mathrm{s}$. 


\section{Estudos eletrocatalíticos com filmes híbridos de porfirinas supramoleculares e nanopartículas de ouro}

A eletrocatálise é uma das áreas mais importantes da eletroquímica moderna, estando relacionada com problemas atuais fundamentais como a conversão eletroquímica de energia considerando a proteção ao meio ambiente e o desenvolvimento de sensores eletroquímicos.

O uso do termo eletrocatálise nos dias de hoje tornou-se bastante abrangente, referindo-se genericamente ao efeito da natureza do material do eletrodo sobre a cinética de qualquer reação eletroquímica. Na maioria dos casos, o ideal é que não ocorra nenhum tipo de transformação do eletrodo durante a ocorrência da reação, servindo este apenas como um mediador (oxidativo ou redutivo) de transferência de elétrons, envolvendo uma prévia etapa de interação/ativação do substrato.

A pesquisa em eletrocatálise tem sido abordada em relação a inúmeros aspectos importantes, dos quais se destacam a determinação do mecanismo e da cinética de reações eletroquímicas de interesse, a identificação da natureza e propriedades das espécies que participam da reação e a influência da interface (incluindo espécies adsorvidas) sobre a cinética e o mecanismo da reação.

A eletrocatálise em eletrodos modificados envolve a participação direta do material adsorvido, ancorado ou depositado sobre a superfície de eletrodos de estado sólido. Logo, a reação de transferência eletrônica é promovida pelo filme ou 
molécula mediadora. Comparando-se com uma reação que ocorre num eletrodo metálico, por exemplo, verifica-se que o sobrepotencial pode ser significativamente diminuído quando se usam eletrodos quimicamente modificados, dependendo da natureza e da atividade eletrocatalítica do material mediador. Ou seja, é possível transferir a atividade eletroquímica das moléculas que apresentam determinadas propriedades de interesse para a superfície dos eletrodos, tornando possível a sistematização dos estudos.

A modificação de superfícies de eletrodos com filmes moleculares tem sido estudada com grande interesse devido à possibilidade de exploração da cinética de transferência eletrônica em ambientes químicos bem controlados.

Assim como na química supramolecular ${ }^{[50]}$, em que, através do planejamento adequado das supermoléculas é possível controlar determinadas propriedades catalíticas e eletrocatalíticas dessas espécies, o planejamento dos eletrodos através da imobilização/deposição controlada das espécies moleculares ou de outros materiais, também constitui uma interessante estratégia na área de eletrocatálise. A modificação da superfície do eletrodo é, na maioria dos casos, necessária para que se atinjam os propósitos desejados, como por exemplo, a obtenção de novas interfaces para sensores amperométricos. Ou seja, é possível controlar as reações de eletrodos modificando a natureza da interface eletrodo-solução e selecionando-se criteriosamente o potencial aplicado à célula. 
As espécies químicas imobilizadas na superfície do eletrodo podem estar na forma de filmes finos ou ainda distribuídos de maneira bidimensional em monocamadas. Cada tipo de filme apresenta suas peculiaridades.

Os filmes finos permitem a imobilização de muitas monocamadas da espécie ativa na superfície modificada, ampliando consideravelmente a resposta eletroquímica. $O$ trabalho com monocamadas também é desejável, pois se pode ter um controle mais preciso do grau de funcionalização da superfície ${ }^{[51]}$. Todavia, tendem a ser muito frágeis e uma sensibilidade adequada somente é conseguida quando a atividade eletrocatalítica do material é excepcionalmente grande, como no caso das metaloporfirinas e compostos análogos. Os processos de lixiviação também ocorrem com filmes de múltiplas camadas ou filmes espessos, sendo a deposição de filmes poliméricos, por exemplo por eletropolimerização, uma estratégia bastante atraente, Neste caso, a solubilidade do material é diminuida a praticamente zero devido a formação de espécies oligoméricas ou poliméricas, que podem ou não formar ligações cruzadas. Enfim, o tipo de filme a ser empregado irá variar conforme o tipo de enfoque analítico que se deseja obter.

A denominação eletrodo quimicamente modificado (EQM) foi inicialmente utilizada na eletroquímica por Murray e colaboradores ${ }^{[52]}$, para designar eletrodos com espécies quimicamente ativas convenientemente imobilizadas na superfície desses dispositivos. Esses eletrodos são frequentemente preparados pela modificação de uma superfície condutora para obter funções específicas desejadas, cujas propriedades são diferentes do substrato não modificado. 
As propriedades dos eletrodos modificados dependem da formação e das características do filme formado na superfície do eletrodo. Uma das principais vantagens dos eletrodos quimicamente modificados é a sua capacidade de catalisar a oxidação de algumas espécies que exibem elevado potencial em eletrodos não modificados, aumentando assim sua sensibilidade e seletividade.

O uso de reagentes moleculares para a manipulação das propriedades da superfície do eletrodo tem ampla aplicação em diversas áreas incluindo conversão e armazenamento de energia, displays, sensores e muitos tipos de arranjos microeletrônicos.

O uso de estratégias baseadas na formação de sistemas supramoleculares ${ }^{[53,54]}$, através da coordenação de complexos de metais de transição às piridil porfirinas, tem levado à obtenção de catalisadores e eletrocatalisadores interessantes. Nesses sistemas catalíticos há interações sinérgicas entre as partes componentes das supermoléculas constituintes dos filmes, melhorando as propriedades condutoras e eletrocatalíticas. Tais propriedades podem ser moduladas de modo a se obter respostas eletrocatalíticas para substratos de interesse químico e comercial, tais como ácido ascórbico, sulfito, nitrito, peróxido de hidrogênio, NADH, dopamina, hidrazina, entre muitos outros. Além disso, metaloporfirinas também têm sido extensivamente empregadas na modificação de superfície de eletrodos devido às suas excelentes propriedades eletroquímicas e eletrocatalíticas. 
Voltamogramas cíclicos dos eletrodos modificados com AuNP e porfirinas (obtidos conforme descrito anteriormente na seção 2.7) foram obtidos na presença de concentrações crescentes de diversos substratos, visando o estudo de seu comportamento eletrocatalítico e posterior possibilidade de aplicação na área de sensores amperométricos.

A morfologia do material também se constitui um parâmetro importante para se compreender melhor as propriedades desses novos filmes. Imagens obtidas através de Microscopia Eletrônica de Varredura (MEV) de um filme de 4TPyP e AuNP sobre um eletrodo de FTO mostram que a superfície do eletrodo apresenta um recobrimento homogêneo de AuNP já nas primeiras camadas, como pode ser visualizado na Figura 7.1 a seguir. A amostra em questão tem apenas duas camadas, mas um recobrimento mais ou menos homogêneo pode ser observado numa ampliação de 100.000 e 200.000 vezes.
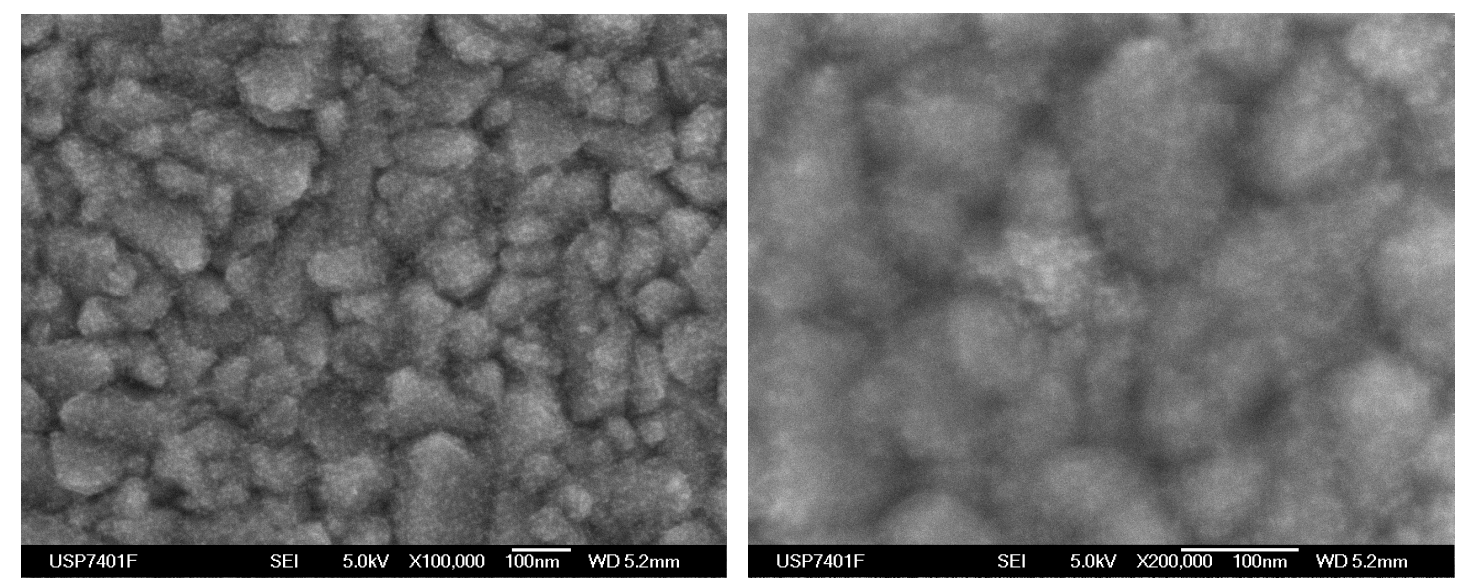

Figura 7.1: Imagens de microscopia eletrônica de varredura (MEV) do filme de AuNP/4TPyP sobre eletrodos de FTO, com ampliação de 100.000 e 200.000 vezes. 
Os filmes obtidos foram empregados para se verificar a resposta eletrocatalítica para oxidação de nitrito, sulfito, ácido ascórbico e peróxido de hidrogênio. Todos os experimentos foram realizados por voltametria cíclica numa célula eletroquímica convencional de três eletrodos, sendo o de trabalho um eletrodo de FTO modificado com um dos filmes híbridos, o de referência foi o de $\mathrm{Ag} / \mathrm{AgCl}$ $(\mathrm{KCl}=1,0 \mathrm{M})$ e o contra-eletrodo um fio de platina. Para os filmes obtidos a partir de porfirinas metaladas (Fe3TPyP e Co3TPyP) e para o de 3TPyP/AuNP/Rh (aquele que apresenta o complexo de ródio apenas na última camada) foi utilizada uma solução tampão acetato de sódio $0,16 \mathrm{M}$ / ácido acético $0,1 \mathrm{M}(\mathrm{pH} 5,0)$, cujo volume inicial na célula eletroquímica (antes de qualquer adição de analito) era de 2,5 mL. A velocidade de varredura foi de $0,05 \mathrm{~V} / \mathrm{s}$. Para os demais filmes utilizando porfirina base livre, as condições experimentais foram as mesmas exceto pelo uso de tampão fosfato em lugar do tampão acetato e pela velocidade de varredura, que foi variada.

\subsection{Oxidação eletrocatalítica de nitrito}

Os alimentos perdem, naturalmente, o sabor devido ao envelhecimento e à exposição a agentes como umidade, oxigênio, bactérias e fungos. Com a finalidade de evitar esse tipo de degradação, as indústrias alimentícias adicionam alguns tipos de aditivos aos seus produtos, como por exemplo ácido ascórbico, sulfito de sódio e nitrito de sódio numa tentativa de evitar sua oxidação e conseqüente perda de sabor. 
Esses aditivos atuam como agentes anti-oxidantes que inibem a atividade enzimática, prevenindo a formação de substâncias que possam vir a deteriorar a aparência e a qualidade dos produtos alimentícios industrializados. Porém, a adição desses aditivos deve ser feita de maneira controlada, de modo a estar de acordo com a legislação em vigor, que estabelece a quantidade máxima que pode ser empregada em cada caso. Em vista disso, fica evidente a necessidade de se monitorar e quantificar a concentração dessas substâncias na indústria alimentícia.

A monitoração dessas espécies também se faz necessária em outros setores além do ramo alimentício, como por exemplo, o industrial, agrícola e médico, dentre muitos outros. No que se diz respeito ao meio ambiente, o uso de fertilizantes, por exemplo, é uma fonte de contaminação de nitratos e nitritos em fontes de água potável.

Além disso, algumas substâncias mesmo em concentrações muito baixas são bastante prejudiciais ao organismo humano ${ }^{[55,56]}$. O nitrito, por exemplo, é apontado como causador de aparecimento de câncer e deformações quando injetado em animais. O emprego incorreto ou indiscriminado do nitrito no processamento das carnes apresenta riscos toxicológicos com efeitos indesejáveis à saúde dos consumidores, podendo levar à metahemoglobinemia ${ }^{[57]}$, ou seja, a conversão irreversível da hemoglobina em metahemoglobina, fato este que compromete seriamente o transporte de oxigênio. Outra conseqüência da ingestão de nitritos é o fato de que este, em contato com a mucosa estomacal pode levar à formação de nitrosaminas, que são substâncias cancerígenas ${ }^{[58,59]}$ para a mucosa gástrica. 
Essas substâncias podem ser formadas no estômago humano pela interação entre os nitritos, nitratos e outras substâncias do conteúdo gástrico.

O potencial de oxidação padrão ${ }^{[60]}$ do $\operatorname{par} \mathrm{NO}_{3}{ }^{-} / \mathrm{NO}_{2}{ }^{-}$é relativamente alto, $\mathrm{E}^{0}=$ 0,94V. Dentre os métodos analíticos mais comuns empregados para quantificação desta espécie podem ser encontradas técnicas espectrofométricas na região do visível [61] até técnicas baseadas no uso de dispositivos como sensores amperométricos empregando porfirinas tetrarutenadas na forma de filmes ${ }^{[62]}$.

A Figura 7.2 a seguir traz os voltamogramas de um eletrodo de FTO modificado pelo filme 3TPyP/AuNP/Rh. Esse filme apresenta três camadas de AuNP e três de 3TPyP e uma última monocamada (a mais externa) de acetato de ródio. Esses voltamogramas foram obtidos à medida que alíquotas de uma solução estoque de nitrito foram adicionadas, num tampão acetato $\mathrm{pH} 5$. $\mathrm{O}$ experimento foi realizado em meio ácido, pois os processos de oxidação de nitrito são dependentes da concentração de prótons. 


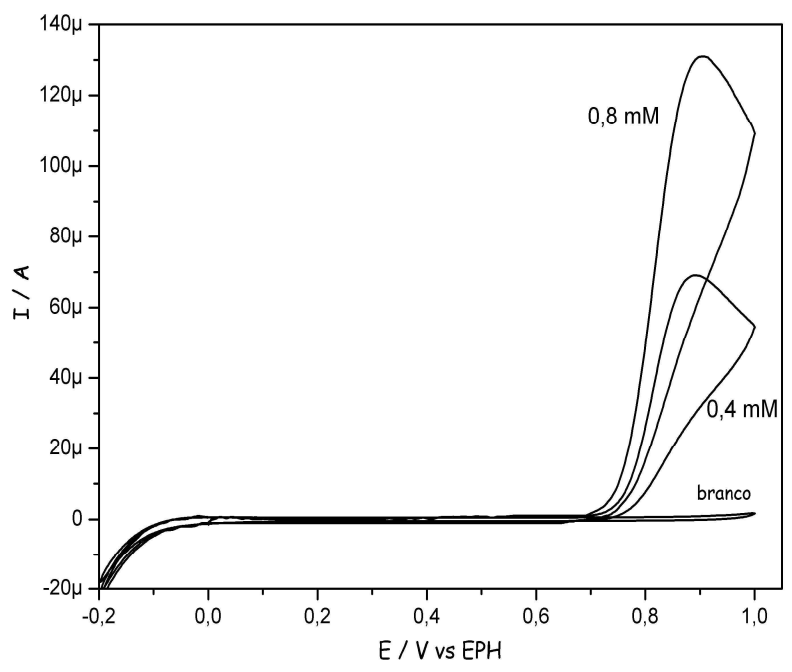

Figura 7.2: VC do eletrodo de FTO modificado pelo filme híbrido de 3TPyP/AuNP, com uma monocamada de acetato de ródio coordenado apenas na última camada, na presença de concentrações crescentes de nitrito. Branco se refere ao voltamograma na ausência de nitrito.

Percebe-se que há um aumento da intensidade da corrente anódica, em torno de $0,9 \mathrm{~V}$ correspondente ao processo de oxidação do nitrito a nitrato. Isso indica que a transferência eletrônica mediada pelo filme é rápida, ou seja, a presença do filme aumenta a velocidade de oxidação do nitrito em solução pelo eletrodo. Nota-se que a intensidade das correntes de pico de oxidação aumenta proporcionalmente ao aumento da concentração do analito.

Ao se analisar a faixa de potenciais negativos do voltamograma apresentado na Figura 7.2 verifica-se que não existem ondas eletrocatalíticas no pH adotado para essas medidas, evidenciando a irreversibilidade daquele processo.

O comportamento voltamétrico para outros tipos de eletrodos de FTO modificados com filmes de M-TPyP/AuNP, onde M-TPyP são meso- 
tetrapiridilporfirinas metaladas com metais da primeira série de transição tais como Co(III) e Fe(III), também foram estudados nas mesmas condições experimentais descritas anteriormente. Filmes constituídos de AuNP e porfirinas metaladas também apresentaram interessantes respostas para a oxidação deste analito.

A atividade eletrocatalítica dos filmes constituídos a partir de Fe3TPyP/AuNP e Co3TPyP/AuNP (10 camadas), foi bastante elevada para a reação de oxidação de nitrito, em pH 5,0, conforme pode ser visto na Figura 7.3 a seguir. É possível notar que os voltamogramas da Figura $7.3 \mathrm{~A}$ apresentam onda de oxidação em $0,82 \mathrm{~V}$ significativamente mais finas que da Figura 7.3 B sugerindo que Fe3TPyP/AuNP é um eletrocatalisador mais eficiente que o respectivo derivado de Co3TPyP. Essas características se aplicam também para a onda de redução em torno de $-0.1 \mathrm{~V}$, provavelmente associado com a redução de dioxigênio residual. A adição de nitrito faz com que essa onda catódica de média intensidade seja intensificada, porém, não varia significativamente mesmo dobrando-se a concentração do analito de 0,4 para $0,8 \mathrm{mM}$. 

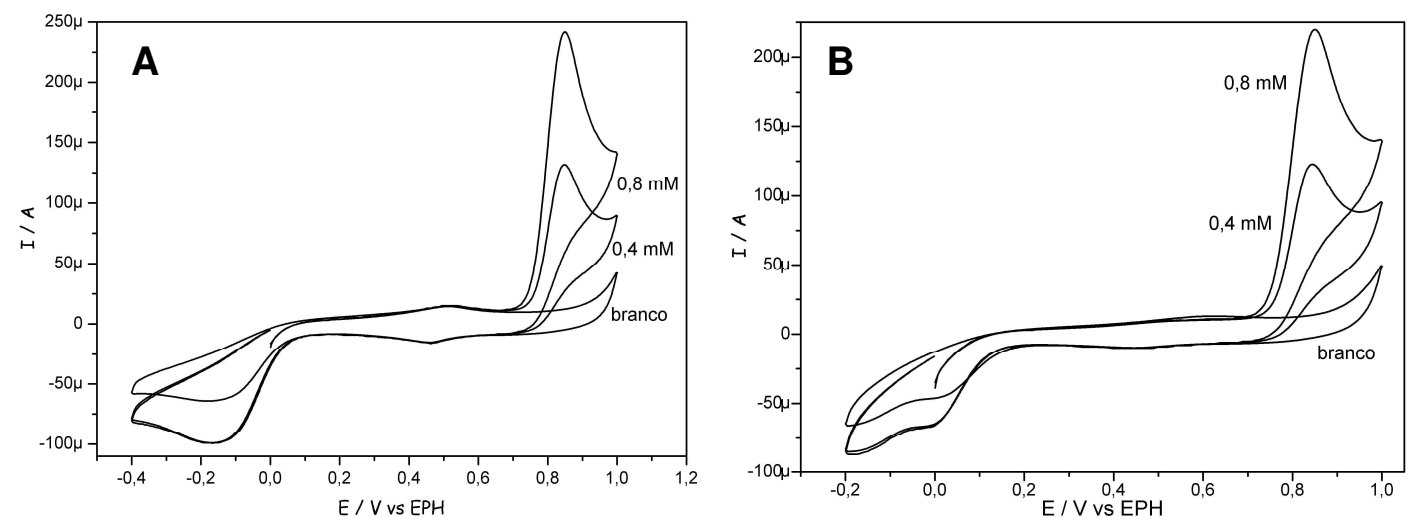

Figura 7.3: VC dos eletrodos de FTO modificado com filme de (A) Fe3TPyP/AuNP e (B) Co3TPyP/AuNP (10 monocamadas), na presença de concentrações crescentes de nitrito em tampão acetato, pH 5 e velocidade de varredura de $50 \mathrm{mV} / \mathrm{s}$.

Como no caso anterior, percebe-se que há um aumento da corrente de pico anódico em torno de $0,85 \mathrm{~V}$, proporcional à concentração do substrato, evidenciando a rápida transferência eletrônica mediada pelo filme, o que faz com que a resposta para nitrito seja intensificada nessa região.

Estes voltamogramas apresentam ainda ondas eletrocatalíticas em regiões de potenciais negativos. Observando-se essa região, pode-se verificar a existência de uma onda catódica de média intensidade mesmo antes da adição do substrato (curva denominada branco na figura). A adição de nitrito em ambos os sistemas faz com que essa onda catódica de média intensidade do branco seja levemente intensificada, porém, este comportamento não continua com o aumento da concentração do analito, pois quando se adiciona a segunda alíquota de nitrito ao sistema (concentração de 0,8 mM), não há mudanças significativas de corrente. 


\subsection{Oxidação eletrocatalítica de sulfito}

Assim como o nitrito, o sulfito também é bastante utilizado pelas indústrias de alimentos, sendo classificado neste contexto como um aditivo alimentar. $\mathrm{O}$ sulfito atua inibindo a deterioração provocada por bactérias, fungos e leveduras em alimentos ácidos, além de dificultar reações de escurecimento enzimático e não enzimático durante processamento e estocagem, melhorando a aparência final dos produtos ${ }^{[63]}$. É frequentemente usado em vinhos e frutas secas como conservante.

Os sulfitos são bastante utilizados na indústria de vinhos devido à sua capacidade de eliminar bactérias e leveduras indesejáveis ao processo e também

por auxiliar na extração de pigmentos. Apresentam ainda ação antioxidante [64] protegendo os diversos compostos responsáveis pelo padrão sensorial apresentado pelos vinhos, mantendo sua qualidade.

Além do uso como aditivo alimentar, o sulfito também encontra aplicação na indústria farmacêutica, onde é usado para manter a estabilidade e potência de certos medicamentos, além de prevenir a deterioração oxidativa.

Apesar da ampla utilização de sulfitos na indústria de alimentos, inúmeros efeitos adversos ${ }^{[65,66]}$ à saúde humana têm sido relacionados à ingestão desses aditivos alimentares, entre eles náusea, irritação gástrica local, urticária e broncoespasmos em indivíduos asmáticos sensíveis. Assim, também se faz necessária a monitoração e quantificação da concentração dessa espécie não só na indústria de alimentos e bebidas, mas também na área farmacêutica, uma vez que 
altas quantidades de sulfito podem causar sabor e aroma desagradáveis, além das sérias conseqüências à saúde humana.

Filmes supramoleculares híbridos a partir de porfirina tetracoordenada a complexos dinucleares de ródio (3TPyP-Rh) e nanopartículas de ouro também foram montados camada por camada sobre eletrodos de FTO modificados com ácido isonicotínico usando-se o método de montagem coordenativa. Este filme, em contraste aos demais, apresenta um ligante 4-MPy, que faz o papel de molécula ponte entre as AuNP e a próxima camada do filme, neste caso, a supermolécula de porfirina ródio. A figura a seguir traz uma representação esquemática desse filme nanoestruturado de supermolécula e nanopartícula de ouro.
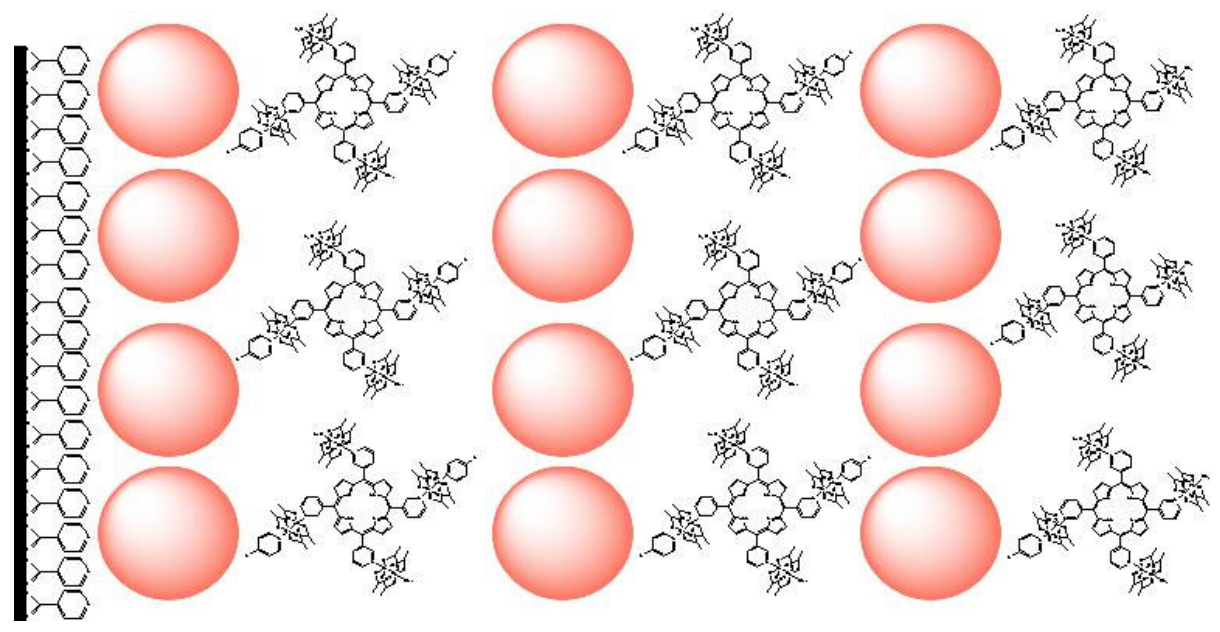

Figura 7.4: Esquema do filme nanoestruturado a partir de supermolécula de porfirina ródio e AuNP, tendo 4-MPy como ligante ponte.

Conforme dito anteriormente, o crescimento do filme foi acompanhado por espectroscopia UV-vis (Figura 2.3) e observou-se que as absorbâncias da banda 
Soret da porfirina aumentam linearmente em função do aumento das bicamadas no filme.

O potencial de oxidação padrão ${ }^{[67]}$ do par $\mathrm{HSO}_{4}^{-} / \mathrm{H}_{2} \mathrm{SO}_{3}$ em meio ácido é $\mathrm{E}^{0}=$ $0,172 \mathrm{~V}$, e em $\mathrm{pH} 6,8, \mathrm{E}=-0,62 \mathrm{~V}$. Apesar de ser bem mais baixo que o potencial redox do nitrito, apresenta um sobrepotencial elevado devido à cinética ser bem mais lenta. Além disso, geralmente, a reação de oxidação do sulfito leva ao envenenamento dos eletrodos sólidos convencionais, diminuindo significativamente a intensidade da corrente já nos primeiros ciclos. O uso de eletrodos quimicamente modificados consiste numa saída estratégica para esse tipo de problema. Alguns métodos analíticos empregados para a quantificação desta espécie utilizando dispositivos baseados em porfirinas supramoleculares já foram descritas pelo grupo [68,69]. Existem também métodos específicos baseados em sensores eletroquímicos ${ }^{[70]}$ para determinação de sulfitos em vinhos.

Este filme anteriormente detalhado (da Figura 7.4) também foi empregado para se verificar a resposta eletrocatalítica da oxidação de sulfito, usando-se para isso, tampão fosfato de $\mathrm{pH}$ 6,8 e o mesmo arranjo experimental descrito anteriormente. Os voltamogramas cíclicos do filme na presença de concentrações crescentes de sulfito (adição de alíquotas da solução estoque de sulfito, $1,58.10^{-2} \mathrm{M}$ ) são mostrados a seguir.

$\mathrm{Na}$ figura 7.5C observa-se que há uma intensificação da corrente de pico anódico, revelando um pico em torno de $0,6 \mathrm{~V}$, correspondente ao processo de oxidação do sulfito. Este potencial é coincidente com o potencial de oxidação do 
acetato de ródio, conforme mostrado anteriormente, indicando que a oxidação do sulfito a sulfato está sendo mediada pela espécie $\left[R h^{3+}-\mathrm{Rh}^{2+}\right]$ gerada eletroquimicamente. Sucessivas adições de sulfito ao sistema revelaram que a intensidade da corrente anódica aumenta linearmente em função da concentração deste substrato. Além disso, os resultados experimentais após vários ensaios sucessivos de oxidação do analito com o mesmo eletrodo modificado indicaram uma boa estabilidade e atividade do filme de 3TPyP-Rh, mostrando que esta supermolécula é um bom modificador de eletrodo.
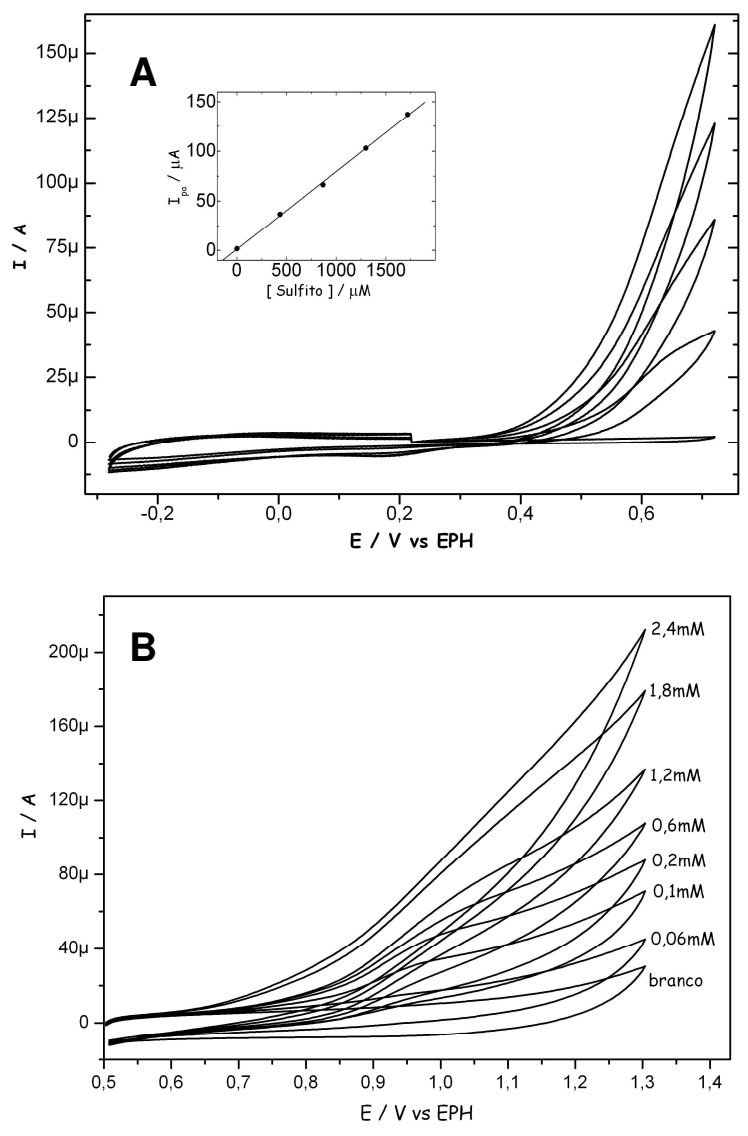


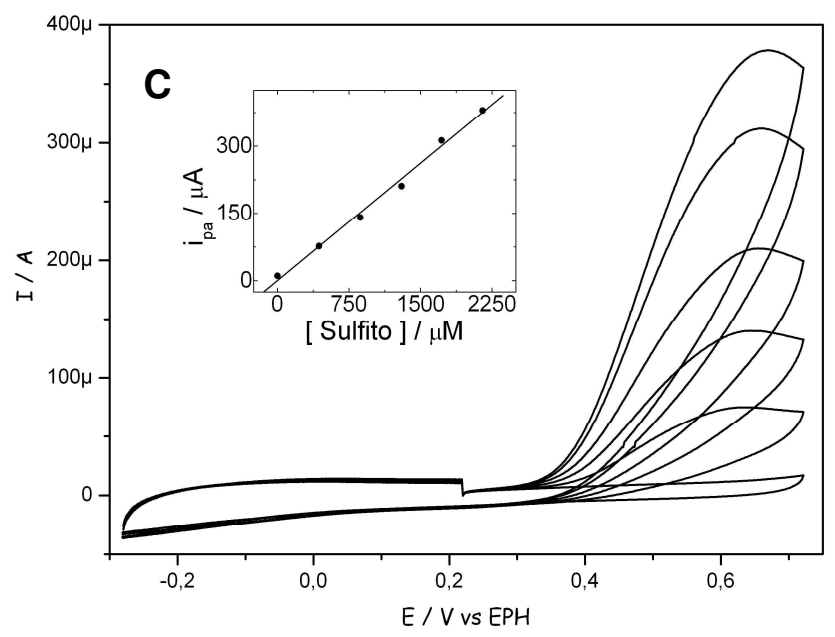

Figura 7.5: VC tampão fosfato ( $\mathrm{pH} 6,8)$ do eletrodo de A: FTO modificado com filme de supermolécula (3TPyP-Rh) apenas com duas bicamadas e AuNP, B: VC do eletrodo de FTO não modificado e C: FTO modificado com filme de supermolécula (3TPyP-Rh) com 10 bicamadas.

Os voltamogramas da figura $7.5 \mathrm{~B}$ se referem às medidas efetuadas adicionando-se alíquotas de sulfito ao sistema, porém com um eletrodo de FTO sem nenhum tipo de modificação superficial. Comparando-se os resultados das três figuras, fica evidente o efeito do filme de supermolécula (3TPyP-Rh) e AuNP sobre a resposta eletroquímica bem como a influência do número de camadas. Nota-se que no eletrodo limpo a corrente é praticamente igual a zero até cerca de $0,8 \mathrm{~V}$, a partir do qual se começa a observar corrente de oxidação do sulfito a sulfato. Contudo, a onda é alargada e consequentemente as correntes são relativamente muito mais baixas que no eletrodo modificado. Logo, o grande deslocamento do potencial de oxidação bem como o aumento da velocidade de transferência de elétrons, pode ser 
atribuído à oxidação do sulfito em solução mediado pelo filme do nanomaterial híbrido.

Resultados eletrocatalíticos similares foram obtidos para o filme de 3TPyP/AuNP/Rh, uma vez que uma onda eletrocatalítica também foi verificada em potencial em torno de 0,6 V, como pode ser visualizado na Figura 7.6 a seguir.

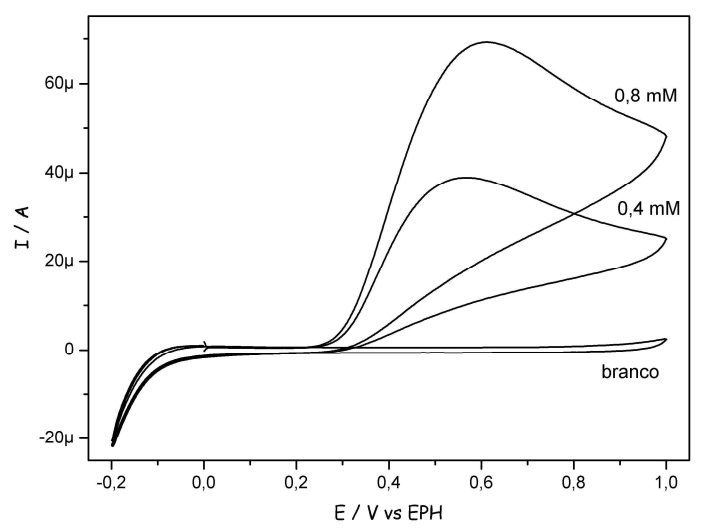

Figura 7.6: VC em tampão acetato (pH 5) do filme 3TPyP/AuNP/Rh (complexo de ródio apenas na última camada) na presença de concentrações crescentes de sulfito, velocidade de varredura de $50 \mathrm{mV} / \mathrm{s}$.

O voltamograma cíclico anterior sugere que este filme com menor quantidade de camadas, já se mostra suficiente para mediar o processo de oxidação do analito. Porém percebe-se que as ondas neste caso se apresentam mais alargadas, sugerindo uma menor eficiência do efeito eletrocatalisador do filme.

A voltametria cíclica dos filmes constituídos a partir de Fe3TPyP e Co3TPyP também mostrou resultados bastante satisfatórios, pois enquanto que eletrodos metálicos apresentam potencial de oxidação para sulfito geralmente acima de 1,0V, devido à presença de um grande sobrepotencial, comum em eletrodos metálicos, os 
eletrodos quimicamente modificados com AuNP e porfirinas metaladas apresentaram uma considerável diminuição desse sobrepotencial para a oxidação deste analito.

Segundo as figuras apresentadas a seguir, é possível verificar que o sulfito está sendo oxidado em potenciais bem mais próximos ao seu potencial padrão. No filme em que é utilizada a Co3TPyP/AuNP (Figura 7.7A), conforme alíquotas de solução de sulfito vão sendo adicionadas há uma intensificação de corrente a partir de $0,20 \mathrm{~V}$, com o máximo do processo de oxidação ocorrendo em $0,36 \mathrm{~V}$. Para o filme derivado do respectivo isômero, Fe3TPyP/AuNP (Figura 7.7B), também há intensificação da corrente a partir de $0,20 \mathrm{~V}$, porém o potencial de pico é ainda menor, sendo o seu máximo observado em torno de 0,24 V.
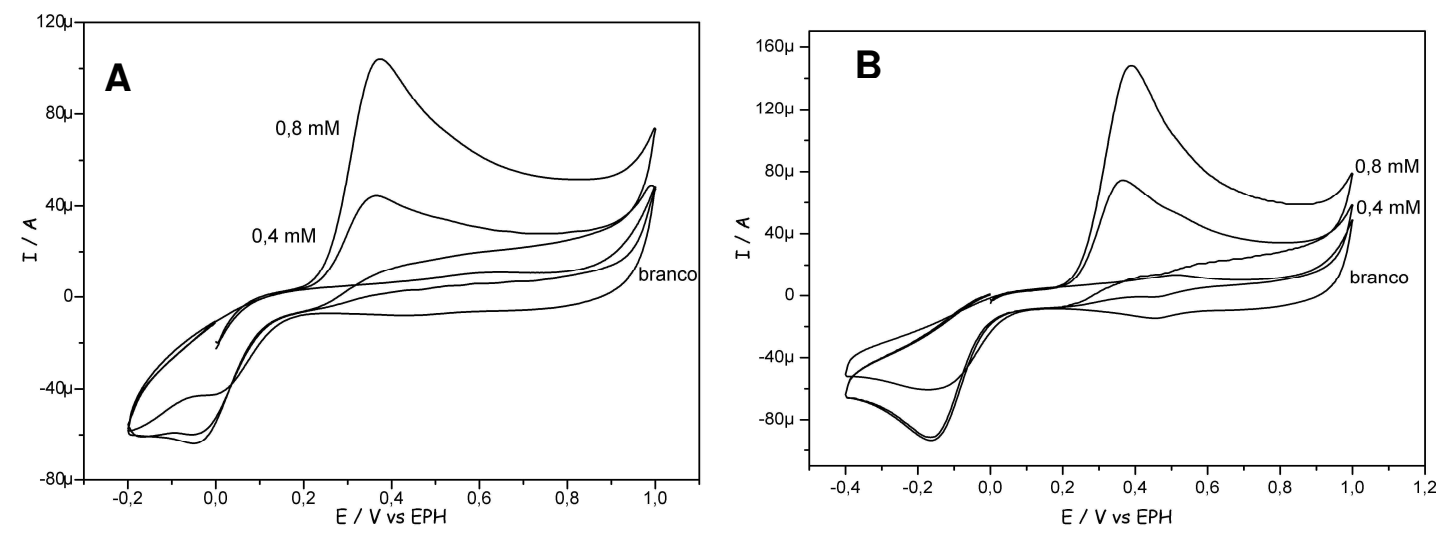

Figura 7.7: VC em tampão acetato (pH 5) com concentração crescente de sulfito dos filmes de A: Co3TPyP/AuNP e B: Fe3TPyP/AuNP, velocidade de varredura de $50 \mathrm{mV} / \mathrm{s}$. 


\subsection{Oxidação eletrocatalítica de ácido ascórbico}

O ácido ascórbico é composto por seis carbonos e é estruturalmente parecido com a glicose e outras hexoses. Tem despertado grande interesse, devido aos efeitos benéficos como vitamina, além de seu grande uso como reagente e como aditivo em alimentos.

A vitamina $C$ é essencial para a formação e resistência das fibras de colágeno no tecido subcutâneo, na cartilagem, nos ossos e nos dentes, sendo que os vasos sanguíneos também dependem da vitamina $C$ para manter a integridade de suas paredes. Uma das manifestações da falta dessa vitamina no organismo é a demora na cicatrização de ferimentos (por falta de substância colágena).

Componente principal da vitamina $\mathrm{C}$, o ascorbato pode reagir diretamente com o peróxido de hidrogênio (água oxigenada), subproduto indesejável de algumas reações enzimáticas do organismo humano, e transformá-lo em moléculas de água inofensivas, em vez de perigosos radicais livres. O ascorbato combate a formação dessas moléculas potencialmente nocivas, participando diretamente nas reações, além de também reciclar moléculas chamadas peroxirredoxinas, que funcionam como catalisadores acelerando a transformação de peróxido de hidrogênio em água.

O ácido ascórbico ocorre naturalmente em uma série de vegetais folhosos (brócolis, salsa, couve, couve, couve-flor, mostarda, nabo, folhas de mandioca,entre outros), legumes (pimentões amarelos e vermelhos) e frutas (caju, goiaba, manga, laranja, acerola, abacaxi, entre outras). Também é frequentemente adicionado 
durante a manufatura de sucos industrializados para aumentar o valor nutricional destes, atraindo consumidores, além de atuar como um bom conservante.

A vitamina $C$ é um agente nutricional e antioxidante, sendo facilmente oxidado pelo ar, sofrendo a oxidação em preferência aos componentes dos alimentos, preservando a sua qualidade.

No Brasil, para a quantificação de ácido ascórbico em medicamentos utilizase a técnica de titulação com iodato de potássio como método oficial ${ }^{[61]}$. Porém ainda é possível a detecção desta substância através de técnicas como espectrofotometria ${ }^{[71]}$, amperometria ${ }^{[72]}$ e quimiluminescência ${ }^{[73]}$.

As figuras a seguir mostram os resultados de voltametria cíclica utilizando os filmes de porfirinas/AuNPs em concentrações crescentes de ácido ascórbico.
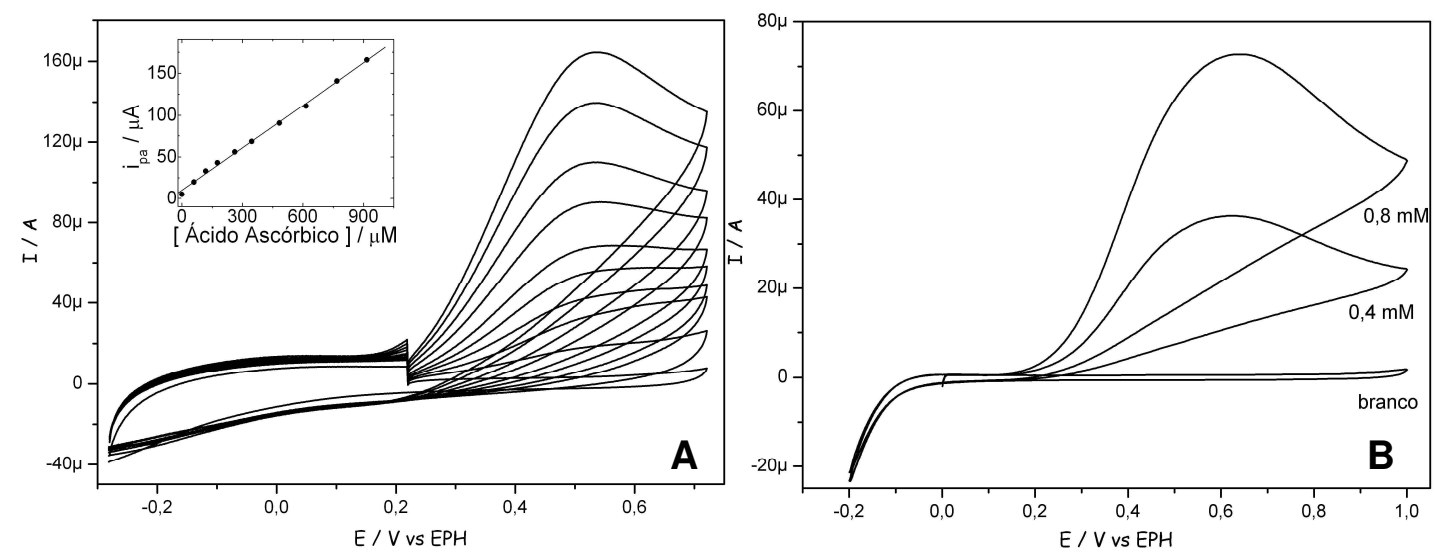

Figura 7.8: VC em tampão acetato (pH 5) com concentração crescente de ácido ascórbico dos filmes de A: supermolécula 3TPyP-Rh/AuNP e B: AuNP/3TPyP/Rh (com acetato de ródio apenas na última camada), velocidade de varredura de $50 \mathrm{mV} / \mathrm{s}$. 
Em ambos os casos é possível perceber que há uma intensificação de corrente a partir de 0,20 V atingindo o máximo de corrente em torno de 0,5 e 0,6 V, para os filmes de 3TPyP-Rh/AuNP e 3TPyP/AuNP, respectivamente. Nota-se que as ondas voltamétricas da Figura 7.8B são mais alargadas que na Figura 7.8A, indicando que este exibe uma maior atividade eletrocatalítica. Estes potenciais se encontram na faixa de potencial do par redox $R h^{11 \prime} R h^{\prime \prime} / R h^{\| \prime} R h^{\prime \prime}$, conforme mostrado anteriormente, indicando que, o processo de oxidação do ácido ascórbico também está sendo mediado pelas espécies $\left[\mathrm{Rh}^{3+} \mathrm{Rh}^{2+}\right]$ geradas eletroquimicamente, assim como na oxidação do sulfito a sulfato. A concentração final é próxima nos dois casos.

Estes materiais são bastante eficientes como mediadores redox para estes processos de transferência de elétrons, uma vez que somente o eletrodo limpo de FTO não apresenta nenhuma onda referente à oxidação da vitamina $\mathrm{C}$ em torno de $0.5 \mathrm{~V}$, mas em potenciais muito mais positivos. A Figura 7.9 se refere aos voltamogramas obtidos em tampão fosfato sendo que a concentração de ácido ascórbico variou de 0 a 0,8 $\mathrm{mM}$. De fato, a corrente anódica começa a aumentar a partir de $0,6 \mathrm{~V}$ e atinge o máximo em torno de $1,4 \mathrm{~V}$, gerando uma onda bastante alargada. Mas, tendo em vista o elevado potencial, esta onda pode englobar a oxidação da água a dioxigênio além da onda de oxidação do ácido ascórbico. 


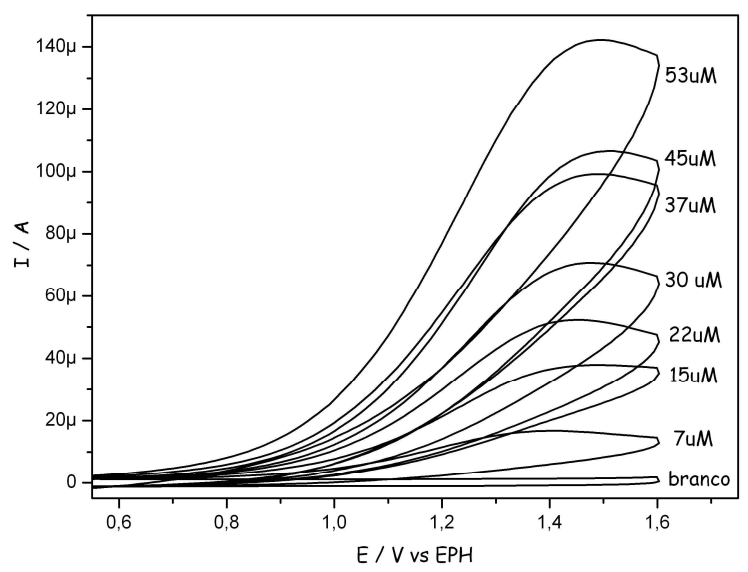

Figura 7.9: Voltamogramas cíclicos em tampão fosfato, pH 6,8, com concentrações crescentes de ácido ascórbico utilizando um eletrodo limpo de FTO, velocidade de varredura de $100 \mathrm{mV} / \mathrm{s}$.

Os filmes de materiais híbridos orgânico-inorgânicos M-TPyP/AuNP, onde $\mathrm{M}=\mathrm{Fe}(\mathrm{III})$ e $\mathrm{Co}(\mathrm{III})$, também foram estudados como materiais ativos para sensores de ácido ascórbico (Figura 7.10). O perfil dos voltamogramas obtidos com esses materiais são similares entre si, porém diferentes daqueles observados para os filmes de 3TPyP-Rh/AuNP e 3TPyP/AuNP. Neste caso a corrente começa a se intensificar em torno de $0,1 \mathrm{~V}$ e sobe rapidamente atingindo o máximo em torno de $0,2 \mathrm{~V}$, ou seja, em potenciais bem menores que no caso dos materiais descritos anteriormente. Assim, pode-se perceber que estes nanomateriais são muito mais ativos como catalisadores de oxidação do ácido ascórbico. Por outro lado, duas ondas de redução mais ou menos bem definidas e de menor intensidade podem ser observados na faixa de 0,0 a -0,2 V. Estes devem estar relacionados com a redução dos produtos de oxidação do ácido ascórbico e possivelmente a presença de oxigênio residual. Verifica-se que é possível modular as propriedades 
eletrocatalíticas dos filmes, simplesmente modificando-se o ligante ponte entre as nanopartículas de ouro.
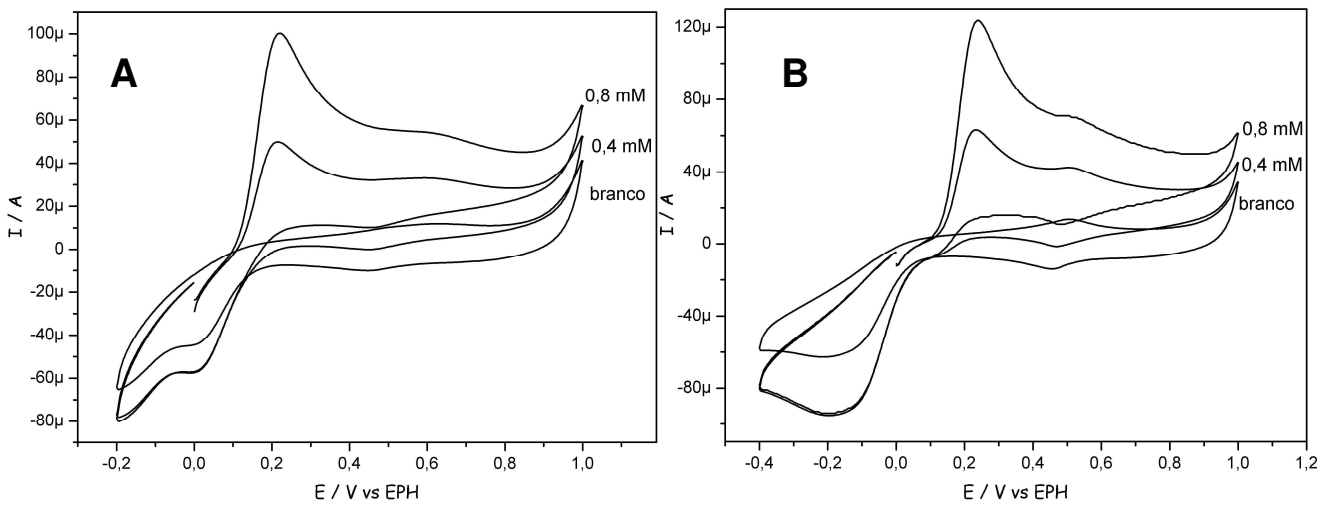

Figura 7.10: VC em tampão acetato (pH 5) com concentração crescente de ácido ascórbico dos filmes de A: CoTPyP/AuNP e B: FeTPyP/AuNP e velocidade de varredura de $50 \mathrm{mV} / \mathrm{s}$.

\subsection{Oxidação e redução de peróxido de hidrogênio}

O peróxido de hidrogênio é um dos oxidantes mais versáteis existentes, sendo possível a sua conversão no radical hidroxila, por meio da utilização de catalisadores adequados, que apresenta reatividade inferior apenas ao flúor.

O peróxido de hidrogênio é um agente oxidante frequentemente utilizado em sínteses orgânicas, processos de descoloração e branqueamento e também no tratamento de efluentes. Porém, além de agente oxidante $\left(\mathrm{H}_{2} \mathrm{O}_{2}+2 \mathrm{H}^{+}+2 \mathrm{e}^{-} \rightarrow\right.$ $2 \mathrm{H}_{2} \mathrm{O}, \mathrm{E}=1,776 \mathrm{~V}{ }^{[67]}$ ), este também pode também ser empregado como agente redutor $\left(\mathrm{H}_{2} \mathrm{O}_{2}+2 \mathrm{OH}^{-} \rightarrow \mathrm{O}_{2}+\mathrm{H}_{2} \mathrm{O}+2 \mathrm{e}^{-}, \mathrm{E}=-0,146 \vee{ }^{[67]}\right)$. Apesar da elevada reatividade, o peróxido de hidrogênio é o produto natural de várias oxidases, em 
inúmeras reações biológicas ${ }^{[74]}$. Todavia, é rapidamente decomposto pelas dismutases presentes no organismo, resultando em oxigênio molecular e água.

O peróxido de hidrogênio encontra aplicações em diversas áreas. Pode-se enfatizar algumas como por exemplo a oxidação de sulfeto de hidrogênio, destruição de cloro residual, redução da demanda química e bioquímica de oxigênio (no reagente de Fenton), entre muitas outras.

A determinação do peróxido de hidrogênio pode ser feita através de técnicas tais como volumetria ${ }^{[75,76]}$, fluorimetria ${ }^{[77]}$, espectrofotometria ${ }^{[78,79]}$ e ainda através de métodos eletroquímicos ${ }^{[80,81]}$. Uma alternativa interessante consiste no uso de BIA (batch injection analysis) associada à amperometria ${ }^{[82]}$ Entretanto, o desenvolvimento de procedimentos ou elementos tais como eletrodos específicos para a determinação, quantificação e monitoração de peróxido de hidrogênio nos mais variados setores de interesse, incluindo a área médica, continua sendo de grande interesse e importância.

Devido à existência de um elevado sobrepotencial para a oxidação do peróxido de hidrogênio, este composto não pode ser convenientemente detectado utilizando-se eletrodos de estado sólido convencionais. Torna-se assim necessário o desenvolvimento de eletrodos quimicamente modificados capazes de diminuir o sobrepotencial, além de torná-lo mais específico e mais sensível.

Os voltamogramas cíclicos dos filmes híbridos de M-TPyP/AuNP de 10 camadas, na ausência e presença de peróxido de hidrogênio, são mostrados na Figura 7.11. Esses voltamogramas foram obtidos ao se adicionar alíquotas de 
peróxido de hidrogênio em solução tampão de $\mathrm{pH}$ 5. Ao se fazer uma análise comparativa dos dois materiais, é possível perceber nitidamente as diferenças no comportamento voltamétrico dos filmes de Co3TPyP/AuNP e Fe3TPyP/AuNP. Nos voltamogramas do primeiro nota-se uma onda de oxidação em $0,6 \mathrm{~V}$, referente à oxidação da água oxigenada, provavelmente a oxigênio. Trocando-se o metal coordenado ao anel porfirínico de $\mathrm{Co}(\mathrm{III})$ para $\mathrm{Fe}(\mathrm{III})$, verifica-se uma grande mudança de comportamento da resposta voltamétrica. O filme de Fe3TPyP/AuNP não apresenta a onda de oxidação do peróxido a oxigênio, como pode ser visualizado na Figura 7.11B. Neste caso, nota-se apenas o aumento da corrente em potenciais acima de $0,9 \mathrm{~V}$ devido à oxidação da água em potenciais positivos.
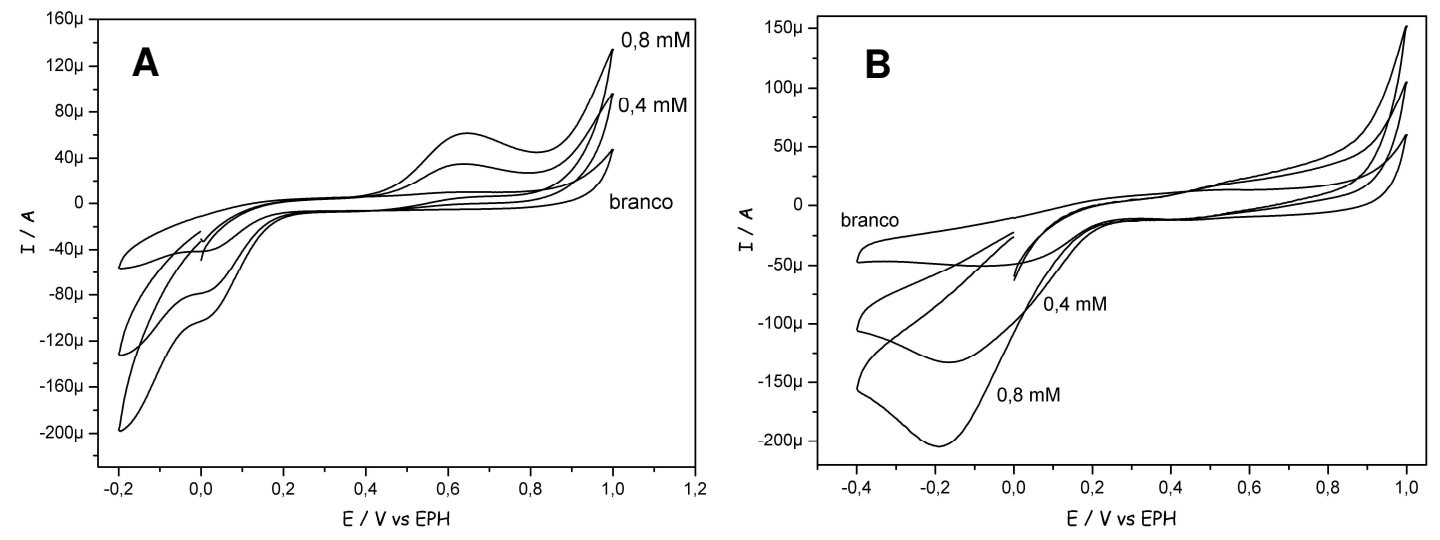

Figura 7.11: VC em tampão acetato (pH 5) em concentração crescente de peróxido de hidrogênio dos filmes de A: Co3TPyP/AuNP e B: Fe3TPyP/AuNP, velocidade de varredura de $50 \mathrm{mV} / \mathrm{s}$.

O comportamento para os processos catódicos também é diferente e está relacionado com as diferenças nas atividades eletrocatalíticas da Fe3TPyP e Co3TPyP para a reação de redução de $\mathrm{H}_{2} \mathrm{O}_{2}$ e $\mathrm{O}_{2}$. O derivado de ferro é um 
conhecido eletrocatalisador para a redução dos dois substratos. Porém, o derivado de cobalto reduz apenas $\mathrm{O}_{2}$ a $\mathrm{H}_{2} \mathrm{O}_{2}$ quando em solução ou imobilizados na superfície de eletrodos. Os resultados obtidos sugerem que os sítios de Co3TPyP estão sendo ativados para a reação de redução de peróxido, pois a onda de redução do $\mathrm{O}_{2}$ é observada em torno de $0,0 \mathrm{~V}$. Por outro lado, os voltamogramas utilizando o filme de Fe3TPyP/AuNP apresentam ondas que são menos resolvidas, gerando uma onda alargada com máximo em torno de $-0,2 \mathrm{~V}$ correspondente à redução daqueles dois substratos. Contudo, pode-se perceber que a redução do $\mathrm{O}_{2}$ ocorre em torno de 0,0 V analisando-se o voltamograma na ausência de peróxido. Logo, neste caso é possível modular as propriedades dos filmes híbridos apenas através da modificação do íon de metal de transição coordenado ao anel porfirínico, conferindo diferentes características ao nanomaterial.

Um estudo similar foi realizado utilizando-se eletrodos modificados com filme de 3TPyP/AuNP/Rh (acetato de ródio apenas na última camada) com o intuito de se confirmar as variações das respostas voltamétricas em função da modificação das espécies moleculares presentes no nanomaterial híbrido. Assim, os voltamogramas cíclicos obtidos à medida que alíquotas de peróxido de hidrogênio foram sendo adicionadas ao eletrólito suporte (solução tampão pH 5) são mostrados na Figura 7.12. Percebe-se que a resposta voltamétrica difere bastante das anteriores, como pode ser visualizado a seguir. 


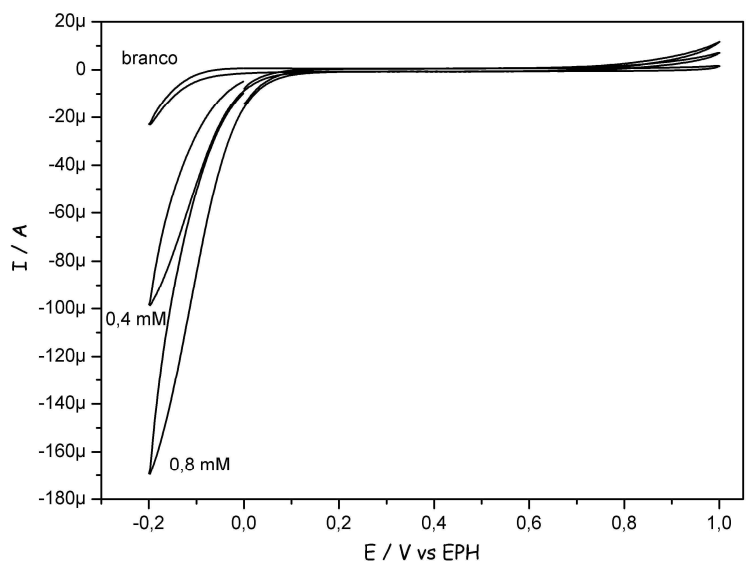

Figura 7.12: Voltamogramas cíclicos tampão acetato (pH 5) do filme de 3TPyP/AuNP/Rh na presença de concentração crescente de peróxido de hidrogênio, velocidade de varredura de 50 $\mathrm{mV} / \mathrm{s}$.

Em função dos resultados observados anteriormente, pode-se afirmar que é possível utilizar estruturas moleculares diferentes como ligantes pontes entre as AuNP para que se obtenha diferentes informações a respeito de um mesmo analito. 


\section{Considerações finais e perspectivas}

Uma nova série de porfirinas obtidas por montagem coordenativa de quatro complexos dinucleares de carboxilato de ródio foi preparada e caracterizada por espectroscopia UV-vis, análise elementar, ressonância magnética nuclear, termogravimetria e voltametria cíclica.

O material anteriormente descrito e caracterizado foi imobilizado em eletrodos de FTO, possibilitando assim a transferência de suas propriedades eletroquímicas para a superfície dos mesmos, e também posteriores estudos de suas propriedades eletrocatalíticas.

Os filmes estudados são eletrocataliticamente ativos para a oxidação de substratos de grande interesse comercial, como ácido ascórbico, sulfito e peróxido de hidrogênio. As melhores características para aplicações em sensores amperométricos foram observadas para os eletrodos modificados com filmes eletrostaticamente montados, camada por camada, contendo AuNPs em sua composição.

Os eletrodos modificados apresentam processos eletrocatalíticos de oxidação daqueles substratos na faixa de 0 a $0,6 \mathrm{~V}$, com sensibilidade para concentrações na faixa de $\mu \mathrm{M}$ até $\mathrm{mM}$. A intensidade de corrente de pico de oxidação é linearmente intensificada à medida que se aumenta a concentração dos substratos, ou seja, a 
resposta da corrente obtida é proporcional à concentração dos substratos em questão.

Assim, esses novos nanomateriais devem ser de grande utilidade na construção de novas interfaces para sensores ou detectores amperométricos de analitos de interesse químico, comercial e ambiental. Outro fator a ser considerado se refere ao fato desses materiais apresentarem uma alta reprodutibilidade, e sensibilidade. Tanto as propriedades quanto a sensibilidade desses materiais nanoestruturados podem ser variadas por meio da modulação do tipo de reagente molecular utilizado na camada depositada. 


\section{Curriculum Vitae}

Nome: Rebeca Evahides Yatsuzuka

Data de Nascimento: 22/10/1981

Local de Nascimento: São Paulo

\section{Formação Acadêmica:}

2000 - 2004: Bacharelado e Licenciatura em Química, Instituto de Química, Universidade de São Paulo, São Paulo.

2005 - presente: Estudante de Mestrado, Departamento de Química

Fundamental, Instituto de Química, Universidade de São Paulo, São Paulo.

\section{Participação no Programa de Aperfeiçoamento de Ensino - PAE:}

QFL 605 - Química Geral para a Física - $2^{\circ} \mathrm{Sem} / 2005$

QFL 605 - Química Geral para a Geologia - $1^{\circ} \mathrm{Sem} / 2006$

QFL 605 - Química Geral para a Física - 2 Sem/2006

\section{Participações em Congressos:}

1. $9^{\circ}$ Simpósio Internacional de Iniciação Científica da Universidade de São Paulo-2001.

2. $10^{\circ}$ Simpósio Internacional de Iniciação Científica da Universidade de São

$$
\text { Paulo- } 2002 .
$$


3. Síntese e Caracterização da Supermolécula Obtida da Coordenação de Dinuclear de Ródio à Porfirina, Rebeca Yatsuzuka, André Luiz B. Formiga, Juliano A. Bonacin, Henrique E. Toma, $27^{\circ}$ Reunião Anual da Sociedade Brasileira de Química - 2004.

4. Decomposição Térmica de Nova Supermolécula de Ródio Porfirina, $R$. Yatsuzuka, J. A. Bonacin, A. L. B. Formiga, H. E. Toma. IV CBRATEC Congresso Brasileiro de Análise Térmica e Calorimetria - 2004.

5. Estudo eletrocatalítico de filmes supramoleculares de porfirina tetracoordenada à clusters dinucleares de ródio $\left(\mathrm{Rh}_{2}\left(\mathrm{C}_{2} \mathrm{H}_{3} \mathrm{O}_{2}\right)_{4}\left(\mathrm{H}_{2} \mathrm{O}\right)_{2}\right)$, $29^{\circ}$ Reunião Anual da Sociedade Brasileira de Química - 2006.

6. Nanomateriais Supramoleculares Híbridos Contendo Nanopartículas de Ouro: Estudos Espectroscópicos, Eletroquímicos e Eletrocatalíticos. Ildemar Mayer, Luis F. O. Furtado, Rebeca Yatsuzuka, Henrique E. Toma, Koiti Araki. $29^{\circ}$ Reunião Anual da Sociedade Brasileira de Química - 2006.

7. Caracterização e aplicações de nanomateriais supramoleculares híbridos de porfirinas e nanopartículas de ouro, Rebeca Yatsuzuka, Luis F. O. Furtado, Koiti Araki, $30^{\circ}$ Reunião Anual da Sociedade Brasileira de Química- 2006.

8. Coordinative-Assembly of Supramolecular Hybrid NanoMaterials, Rebeca Yatsuzuka, Luis F.O. Furtado, Henrique E. Toma, Koiti Araki. $2^{\circ}$ International Symposium on Advanced Materials and Nanostructures ISAMN, 2007 


\section{Referências}

1. Drexler, K.E., Proc. Natd Acad. Sci. USA, 1981, 78, 5275.

2. Descalzo, A.B., Martínez-Mañez, R., Sancenón, F. Hoffmann, K., Rurack, K., Angew. Chem. Int. Ed. Engl., 2006, 45, 5924.

3. Lehn, J. M., Angew. Chem. Int. Ed. Engl., 1988, 27, 89.

4. Lehn, J. M., Science, 1985, 227, 849.

5. Lehn, J. M., Supramolecular Chemistry: Concepts and Perspectives; VCH: New York, 1995.

6. Atwood, J. L.; Davies, J. E. D.; MacNicol, D. D.; Vögtle, F.; Lehn, J.-M.; Eds..

7. Toma, H. E. J. Braz. Chem. Soc., 2003, 14, 845.

8. Lehn, J.-M. Science, 2002, 295, 2400.

9. Lehn, J.-M. Proc. Natl. Acad. Sci., 2002, 99, 4763.

10. Toma, H. E. An. Acad. Bras. Ci, 2000, 72, 1.

11. Toma, H. E. Quím. Nova, 1991, 14, 189.

12. Toma, H. E.; Araki, K. Proc. VI Braz. Symp. Electrochem. Electroanal., 1988, 183. 
13. Toma, H. E.; Araki, K. Proc. VII Simp. Bras. Eletroquím. Eletroanal., 1990, 197.

14. Toma, H. E.; Araki, K. J. Chem. Res.-S, 1990, 82.

15. Araki, K.; Toma, H. E. J. Electroanal. Chem., 1991, 297, 301.

16. Araki, K.; Toma, H. E. Inorg. Chim. Acta, 1991, 179, 293.

17. Araki, K.; Santos, P. S.; Toma, H. E. Spectrosc. Lett., 1993, 26, 1417.

18. Araki, K.; Toma, H. E. J. Coord. Chem. 1993, 30, 9-17.

19. Araki, K.; Toma, H. E. J. Photochem. Photobiol. a-Chemistry 1994, 83, 245.

20. Araki, K.; Angnes, L.; Toma, H. E. Adv. Materials, 1995, 7, 554.

21. Araki, K.; Wagner, M. J.; Wrighton, M. S. Langmuir, 1996, 12, 5393.

22. Azevedo, C. M. N.; Araki, K.; Angnes, L.; Toma, H. E. Electroanalysis, 1998, 10, 467.

23. Ravanat, J. L.; Cadet, J.; Araki, K.; Toma, H. E.; Medeiros, M. H. G.; Di Mascio, P. Photochem. Photobiol. 1998, 68, 698.

24. Araki, K.; Araujo, A. L.; Toyama, M. M.; Franco, M.; Azevedo, C. M. N.; Angnes, L.; Toma, H. E. J. Porph. \& Phthalocyanines 1998, 2, 467.

25. Azevedo, C. M. N.; Araki, K.; Toma, H. E.; Angnes, L. Anal. Chim. Acta 1999, $387,175$. 
26. Araki, K.; Toma, H. E. Electrochim. Acta, 1999, 44, 1577.

27. Dovidauskas, S.; Toma, H. E.; Araki, K.; Sacco, H. C.; lamamoto, Y. Inorg. Chim. Acta 2000, 305, 206.

28. Toyama, M. M.; Demets, G. J. F.; Araki, K.; Toma, H. E. Electrochem. Commun. $2000,2,749$.

29. Araki, K.; Lima, S. D.; Winnischofer, H. An. Acad. Bras. Cienc., 2000, 72, 27.

30. Toma, H. E.; Araki, K. Coord. Chem. Rev, 2000, 196, 307.

31. Bard, A. J. Integrated Chemical Systems. A Chemical Approach to Nanotechnology; John Wiley \& Sons, Inc.: New York, 1994.

32. Rocha, J.R., Demets, G.J.F., Bertotti, M., Araki, K., Toma, H.E., J. Eletroanal. Chem. 69, 526, 2002.

33. Boyar, E. B., Robinson, S. D. Coord. Chem. Rev, 1983, 55, 109.

34. Cotton, F. A., Walton, R. A. Multiple bonds between metal atoms; John Wiley e Sons, New York, 1982.

35. Bear, J. L., Howard, R. A., Korp,J. E., Inorg. Chim Acta, 1979, 32, 123.

36. Das, K., Bear, J. L., Inorg. Chem, 1976, 15, 2093. 
37. Drago, R. S., Tanner, S. P., Richman, R. M., Long, J. R., J. Am. Chem. Soc, 1979, 101, 2897.

38. Toma, H. E.; Araki, K. , Ciência Hoje, 2005, 37, 24.

39. Faraday, M., Phil. Trans. Roy. Soc. 1857, 147, 145

40. Johnson, S. A., Hunt, H. R., Neumamm, H. M., Inorg. Chem., 1963, 5, 960.

41. Nazarova, L.A., Chernyaev, I. I., A.S. Morozova, Russ. J. Inorg. Chem. 1965, 10, 291.

42. Rempel, G.A., Legzdins, P., Smith, H. Wilkinson, G. Inorganic Syntheses, 1972, $13,90$.

43. Das, K., Simmons, E. L., Bear, J. L., Inorg. Chem. 1977, 16, 1268.

44. Turkevitch, J., Stevenson, P.C., Hillier, J. Discuss Faraday Soc. 1951, 11, 55.

45. Brust M., Walker M., Bethell D., Schiffrin D.J., Whyman R.J., J. Chem.

Soc. Chem. Commun., 1994, 801.

46. Araki K., Mizuguchi E., Tanaka H., Ogawa T., J. Nanoscience and Nanotech., $2006,6,708$.

47. Halliwell, C. M, Cass, A. E. G., Anal. Chem., 2001, 73, 2476.

48. Gouterman, M. J. Mol. Spectrosc., 1961, 6,138. 
49. Fouad, N. E., Mohamed, M. A., Zaki, M. I., Knozinger, H., J. Anal. Appl. Pyrol., 2000, 53, 185.

50. Araki, K., Toma, H.E., Supramolecular porphyrins as electrocatalysts, in N-4 Macrocyclic Metal Complexes, Zagal, JH, Bedioui F, Dodelet, J-P Eds., Springer, 2006, p 255.

51. Murray, R. W.; Electroanal. Chem. 1989, 15, 267.

52. Moses, P.R.; Wier, P.; Murray, R.W.; Anal. Chem. 1975, 47, 1882.

53. Araki, K., Toma, H.E., Química Nova, 2002, 25, 962.

54. Toma, H.E., Química Nova, 1991, 14, 189.

55. Swann, P. F., J. Sci. Food \& Agricult., 1975, 26, 381.

56. Cox, R.D., Frank, C.W., J. Anal. Toxicol. , 1982, 6, 148.

57. Alaburda, J., Nishihara, L., Rev. Saúde Pública, 1998, 32, 2.

58. Huang, Y.G., Ji, Hou,J.D., Mutat. Res. Fund. Mol. Mech. Mutagen. , 1996 7, 358.

59. Wolff, I.A, Wasserma, A.E, Science, 1972, 15, 177.

60. Bard, A.J., Parsons, R. Jordan, J. Standart potencials in aqueous solution, 1st Ed. New York, 1985. 
61. Instituto Adolfo Lutz. Normas analíticas do Instituto Adolfo Lutz. $3^{\mathrm{a}}$ ed. São Paulo, IMESP, 1985, 1, 313.

62. Winnischofer, H., Lima, S.S., Araki, K., Toma, H.E., Anal. Chim. Acta, 2003, 480, 97.

63. L.E.Coker, J. of the Association of Official Analytical Chemists, 1986, 69, 8.

64. Ough, C. S., J. of the Association of Official Analytical Chemists, 1986, 69, 5.

65. Yang, W. H., Purchase, E. C. R., Canadian Medical Association Journal, 1985, 133,865 .

66. Taylor, S. L., et al., Advances in Food Research, 1986, 30,1.

67. Handbook of Chemistry and Physics, CRC Press, 67th ed.

68. Mayer, I., Toma, H.E., Araki, K, J. Eletroanal. Chem, 2006, 590, 111.

69. Azevedo, C.M.N., Araki, K., Toma, H.E., Angnes, L. Anal. Chim. Acta,1999, 387, 175.

70. Granados, M., Maspoch, S., Blanco, M., Anal. Chim. Acta, 1986, 179, 445.

Schumb, W. C.; Satterfield, C. N.; Wentworth, R. L.; Hydrogen Peroxide, Reinhold: New York, 1955. 
71. Hernandez, J., Alonso, A., Almendral, M. J., Garcia, C., Anal. Chim. Acta, 1986, 184, 243.

72. Fogg, A. G., Summan, A. M., Fernandez-Arciniega, M.A., Analyst, 1985, 110, 341.

73. Alwarthan, A. A.; Analyst, 1993, 118, 639.

74. Everse, J.; Everse, K. E.; Grisham, M. B.; Peroxidases in Chemistry and Biology, CRC Press: New York, 1991.

75. Y. T. Didenko and S. P. Pugach, J. Phys. Chem. A, 1994, 98, 9742.

76. N. V. Klassen, D. Marchington and H. C. E. McGovan, Anal. Chem., 1994, 66, 2921.

77. T. R. Holm, G. K. George and M. J. Barcelona, Anal. Chem., 1987, 59, 582.

78. A. C. Pappas, C. D. Stalikas, Y. C. Fiamegos and M. I. Karayannis, Anal. Chim. Acta, 2002, 455, 305.

79. P. A. Clapp, D. F. Evans and T. S. S. Sheriff, Anal. Chim. Acta, 1989, 218, 331.

80. R. C. Matos, J. J. Pedrotti and L. Angnes, Anal. Chim. Acta, 2001, 441, 73.

81. S. B. Khoo, M. G. S. Yap, Y. L. Huang and S. Guo, Anal. Chim. Acta, 1997, 351, 133. 
82. Quintino, M.S.M., Winnischofer, H., Araki, K., Toma, H.E., Angnes, L., Analyst, 2005, 130, 221. 